\title{
Transitional Flow Regime Heat Transfer and Pressure Drop in an Annulus with Non-Uniform Wall Temperatures
}

\author{
Dickson D. Ndenguma, Jaco Dirker*, Josua P. Meyer \\ Department of Mechanical and Aeronautical Engineering, University of Pretoria, Private Bag X20, \\ Hatfield, Pretoria, 0028, South Africa
}

\footnotetext{
*Corresponding author:
}

Email: jaco.dirker@up.ac.za

Phone: +27124202465

\begin{abstract}
An experimental investigation was carried out to determine the average heat transfer coefficients and friction factors in the transitional flow regime of a horizontal concentric annular passage. The flow was in the mixed convection flow regime and was both hydrodynamic and thermally developing. The annular diameter ratio was 0.483 with an inner passage wall diameter of $15.90 \mathrm{~mm}$. The test facility, which consisted of a counter-flow heat exchanger having a heat transfer length of $5.08 \mathrm{~m}$, was operated at different degrees of longitudinal wall temperature uniformity on the inner wall of the annular passage. Both heated and cooled flow applications with water as fluid (cold fluid and hot fluid respectively) were investigated using a conventional annular inlet geometry type. It was found that the degree of temperature uniformity on the inner surface of the annular passage had an influence on the transitional Reynolds number span, the heat transfer coefficients, and friction factors. Depending on the wall temperature uniformity it was found that the critical Reynolds number, based on the Nusselt number results, was approximately between 350 and 500 for a cooled annulus and between 480 and 510 for a heated annulus. The critical Reynolds numbers based on the friction factor results were different from those based on the Nusselt number and was found to be approximately 800 for
\end{abstract}


isothermal flow, between 1000 and 1030 for a cooled annulus, and approximately 1000 for a heated annulus. Correlations for the prediction of the transitional regime Nusselt number and friction factor as a function of among others, the wall temperature uniformity are proposed. The Nusselt number correlation predicts all the experimental data within a $\pm 6 \%$ error band for the heated annulus case and $91 \%$ within a $\pm 6 \%$ error band for the cooled annulus case. The friction factor correlation predicts $95 \%$ the data points, within a $\pm 6 \%$ error band for heated case and all data points within a $\pm 6 \%$ error band cooled annulus case.

Key words: Heat exchanger, Annulus, Annular passage, Diameter ratio, Transition flow, Mixed convection, Developing flow, Wall temperature uniformity, Nusselt number, Colburn $j$-factor, Friction factor. 


\section{Nomenclature}

$a \quad$ Annular diameter ratio, $a=D_{1} / D_{\mathrm{o}}$

$A_{c} \quad$ Cross-sectional area

As $\quad$ Surface area of heat transfer

$B_{1}, B_{2}, B_{3}$ Coefficients

C Constant factor

$c_{p} \quad$ Specific heat

D Diameter

$E_{1}, E_{2}, E_{3}$ Coefficients

EB Energy balance (\%)

F Factor to take into account the dependence on $a$

$f \quad$ Friction factor

$g \quad$ Gravity acceleration

Gr Grashof number, $\mathrm{Gr}=\frac{g \beta_{o}\left(\bar{T}_{i w}-\bar{T}_{b, o}\right) D_{h}^{3}}{v_{o}^{2}}$

$h \quad$ Convection heat transfer coefficient

j Colburn $j$ factor

K Factor to take into account the temperature dependence of fluid properties

$k \quad$ Thermal conductivity

$L_{d p} \quad$ Pressure drop length

Lhx $\quad$ Length of heat transfer

$\dot{m} \quad$ Mass flow rate

$m, n \quad$ Exponent for $\tau$

$\mathrm{Nu} \quad$ Nusselt number, $\mathrm{Nu}=h D_{h} / k$

$\Delta p \quad$ Pressure drop 
$\begin{array}{ll}\text { Pr } & \text { Prandtl number } \\ \dot{Q} & \text { Heat transfer rate }\end{array}$

Re Reynolds number, $\operatorname{Re}=\frac{4 \dot{m}_{o}}{\pi \mu_{o}\left(D_{0}+D_{1}\right)}$

$\mathrm{Ri} \quad$ Richardson number, $\mathrm{Ri}=\frac{\mathrm{Gr}}{\mathrm{Re}^{2}}$

T Temperature

$\bar{T} \quad$ Averaged temperature

$u \quad$ Exponent for $\mathrm{Gr}$

$v \quad$ Exponent for $\operatorname{Pr}$

$V \quad$ Average cross-sectional velocity, $V=\dot{m} /\left(\rho_{o} A_{c}\right)$

$x \quad$ Axial length

$z_{1} \quad$ Exponent for $\mathrm{GrPr} / \mathrm{Re}$

$z_{2} \quad$ Exponent for GrPr

Greek symbols
$\rho \quad$ Density
$\mu \quad$ Dynamic viscosity
$\tau \quad$ Degree of wall temperature uniformity

Subscripts

$0 \quad$ Inner wall of outer tube

$1 \quad$ Outer wall of inner tube

iso Isothermal

$b \quad$ Bulk property 


$\begin{array}{ll}c a & \text { Cooled annulus } \\ d & \text { Diabatic } \\ h & \text { Hydraulic } \\ h a & \text { Heated annulus } \\ i & \text { Inner flow passage } \\ \text { I } & \text { Lower Reynolds number limit of transitional flow regime } \\ \text { II } & \text { Upper Reynolds number limit of transitional flow regime } \\ \text { in } & \text { I n } 1 \text { e t } \\ \text { iw } & \text { On the outside wall of the inner tube } \\ \text { LMTD } & \text { Logarithmic mean temperature difference } \\ o & \text { Annular flow passage } \\ \text { out } & \text { Outlet } \\ \text { ow } & \text { Outer tube wall }\end{array}$




\section{Introduction}

Tube-in-tube type heat exchangers is one of the most common kinds of thermal exchange devices used. They are normally operated in a counter-flow configuration such that the fluid in the inner tube and the fluid in the annular space flow in opposite directions. Although a large body of literature is available for the heat transfer and pressure drop characteristics in the inner tube, less literature is available focusing on the annular flow passage. Among the limited literature for annuli, some correlations and calculation methods do exist for predicting the annular heat transfer coefficient in the turbulent flow regime, including those presented by Gnielinski [1], Swamee et al. [2] and Dirker and Meyer [3]. However, for the transitional flow regime, very little work has been done.

This could be so because most design guidelines advise designers to avoid operating heat exchangers in this flow regime. However, Meyer [4], lists several reasons why heat exchangers often operate in, or close to the transitional flow regime. These include changes in operating conditions, fouling, scaling, replacement of upstream or downstream equipment with different operating characteristics, etc. The introduction of heat transfer enhancement geometries also plays a role. Even though these geometries increase the heat transfer coefficients, it unfortunately also increase the pressure drop. As a result, in many cases pumping power is reduced by decreasing, the mass flow rates (without a significant decrease in heat transfer) which may result in heat exchangers being operated in, or close to the transitional flow regime [5-10].

Because only limited work has been done focusing on the transitional flow regime characteristics in annular flow passages, a brief review of transitional flow regime literature for circular and other cross sectional flow passages need to be considered. In this context, noticeable work has been conducted by Ghajar and coworkers. For instance, for circular flow channels, Ghajar and Tam [11] and Ghajar and Madon [12] observed that the inlet configuration of a flow channel can significantly influence the critical Reynolds number where transition is initiated. In one of their studies the effect of the inlet geometry on the developing and fully 
developed mixed convection for three different types of inlet geometries namely: reentrant, square edged and bell-mouth were investigated. They found that transition from laminar to turbulent flow under isothermal flow condition occurred at Reynolds numbers of $1980-2600,2070-2840$ and $2125-3200$ for the reentrant, the square edged and the bell-mouth inlet, respectively. Further work by Tam and Ghajar [13] showed transition to occur at higher Reynolds numbers than those observed in previous studies. They found that transition from laminar to turbulent flow occurred at Reynolds numbers of $2900-3500,3100-3700$ and $5100-6100$ for the reentrant, the square edged and the bell-mouth inlet, respectively. When different heat fluxes were applied to the test section the values of friction factor and the lower and upper limits of the transition boundaries increased with an increase in the heating rate for a fixed Reynolds number.

Olivier and Meyer [15] did a similar investigation as done by Ghajar and Tam [11] and Tam and Ghajar [13] with the same types of inlets. However, apart from smooth tubes they also investigated enhanced tubes. It was found for enhanced tubes that transition was affected not only by the type of inlet, but also the tube surface roughness. Transition started earlier for the re-entrant inlet type followed by the squared edged and bell-mouthed inlet types. Further investigation with heat transfer [15] showed that inlet disturbances had no effect on the critical Reynolds number. Dirker et al. [16] investigated the effects of different types of inlets in rectangular micro-channels. They considered sudden contraction, bell-mouth and swirl inlet types. They also found that the critical Reynolds number and the transitional behaviour in terms of heat transfer and friction factors were influenced significantly by the inlet flow condition. The transition for their bell-mouth inlet commenced at a Reynolds of 1050 for isothermal tests. This is much lower than the Reynolds number of 2125 found by Ghajar and Madon [12] for their bell-mouth inlet and could have been due to the differences in cross-section size, Grashof numbers, and shape of conduits that were used in the two investigations. Everts et al. [17] investigated the effects of surface roughness on transition in circular tubes. Heat transfer measurements at three different heat fluxes $\left(5.6,8.4\right.$ and $\left.11.4 \mathrm{~kW} / \mathrm{m}^{2}\right)$ were taken for water in a smooth and three roughened tubes with a relative roughness of $0.01,0.02$ and 0.04 , respectively. It was found that 
transition occurred earlier with increasing surface roughness and the heat transfer increased as well, while the secondary flow effects decreased.

Some of the literature discussed so far, which did not consider inlet effects are for fully developed (hydrodynamically and thermally) flow regimes. Practically, many heat exchangers are compact and short in length and do not necessarily operate within the fully developed flow regime. In some cases free convection heat transfer may exist, which in turn creates secondary flow. In their handbook, Kakac et al. [18], in which they reviewed work by Hattori [19] and Nguyen et al. [20], indicated that for mixed convection in a horizontal concentric annulus the secondary flows can strongly distort the velocity and temperature profiles and consequently increase heat transfer coefficients. Mohammed et al. [21] carried out an experimental study on forced and free convective heat transfer in the thermal entry region of horizontal concentric annuli operated with air at a constant inner wall heat flux while the outer annular wall was adiabatic. The investigation covered a Reynolds number range from 200 to 1000 . They found that due to the dominance of free convection, the temperature on the inner surface was higher for low Reynolds numbers compared to that for high Reynolds numbers. The investigation also revealed that the Nusselt number values for thermally developing flow were considerably greater than the corresponding values for fully developed mixed convection over a significant portion of the annulus.

Ciampi et al. [22] performed similar experimental work as Mohammed et al. [21] but with hydrodynamic developed flow of water. Their study focused on the determination of the circumferential variations in the local Nusselt numbers. Their wall boundary condition was also a constant heat flux, and the Reynolds number range was from 2200 to 5000 . Visual inspection showed the flow to be laminar and helicoidal for Reynolds numbers less than a critical value, while for Reynolds numbers above the critical value the helicoidal motion vanished with a subsequent transition to turbulence in the top and side regions of the annular passage. The local Nusselt number at the top of the inner tube was found to be less than, equal to, and greater than that at 
the bottom for cases where the Reynolds number was below the critical value, equal to the critical value and greater than the critical value, respectively. Lu and Wang [23, 24] conducted experiments in tubein-tube heat exchangers to examine the characteristics of a non-fully developed flow with secondary flow in narrow annuli. The outer diameter of their inner tube was $15.93 \mathrm{~mm}$ and the hydraulic diameter was $6.16 \mathrm{~mm}$. In their experimental set-up they used hot water flowing in the inner tube to heat the inner wall of the annular passage. The wall temperature profile on the inner wall was not well defined but the outer wall was adiabatic. Their Reynolds number range, based on the annular hydraulic diameter, was between 10 and 30 000. Their results showed different heat transfer and pressure drop characteristics from those in circular tubes. They also found that the transition based on friction factors occurred at different ranges of Reynolds number compared to the transition based on the heat transfer. The transition based on the heat transfer coefficient occurred at lower Reynolds numbers.

Recent experimental studies on turbulent flow heat transfer coefficients and friction factors in an annular passage are available for both heated and cooled annulus cases. Van Zyl et al. [25] and Prinsloo et al. [26] investigated the effect of heat transfer direction and bulk fluid temperature on heat transfer coefficient and pressure drop in the turbulent flow regime of horizontal annulus. They found that the direction of the heat flux between the inner wall and annular fluid could affect both the heat transfer coefficients and friction factors. Generally, the Nusselt number values for a heated annulus were higher than for cooled annulus and the friction factors for a cooled annulus were higher than for the heated annulus. This behaviour was attributed to the bulk temperature differences during the heating and cooling processes that were considered. The results of Van Zyl et al. [25] showed that a heated annulus had Nusselt numbers which were on average $35 \%$ larger than for the cooled case and that the friction factors for a heated annulus were on average $9 \%$ lower than for a cooled case. They went further to express the heat transfer results in terms of the $j$-factor. Once the effects of the Prandtl number were taken into account their heat transfer coefficient results for a heated and a cooled annulus were in a close agreement with and average percentage difference of only $2.6 \%$. 
A further complication is the influence that the thermal boundary conditions may have on the heat transfer and pressure drop. Most available literature sources consider only uniform heat flux or uniform wall temperature boundary conditions. Although the impact of the thermal boundary condition might not be important in the turbulent flow regime, it is important when considering laminar and transition flow regimes because of the presence and influence of buoyancy driven secondary flow. In general, many real world applications exhibit wall boundary condition types that are neither uniform heat flux, nor uniform wall temperature in nature. This leaves a designer to guess what the conservative limit could be of the heat transfer and pressure drop behaviour. This is especially so if the relative flow rates of the heat transfer fluids are such that there is a significant change in both of the fluids' temperatures along the flow passages. Little to no literature could be found that specifically deals with the influence of the non-uniform thermal boundary wall condition and its impact on fluid flow behaviour in annular flow passages.

Based on the literature, a knowledge gap exists for heat transfer and pressure drop characteristics in the transition flow regime of an annular passage, when the thermal boundary wall conditions are not uniform. It was, therefore, the purpose of this study to experimentally determine the heat transfer and pressure drop characteristics in an annular passage in the transitional flow regime for different inner wall temperature conditions with the outer wall being insulated. Heated and cooled annulus cases were considered across the entire flow regime from laminar to turbulent, but special attention was given to the transitional flow regime. The fluid in the annulus was limited to water and the type of convection was mixed and forced. The boundary wall temperature conditions considered on the inner wall differed from an approximate uniform wall temperature, to different levels of non-uniform wall temperatures. The emphasis in this paper was therefore on the effect which the degrees of wall temperature uniformity has on the lower and upper Reynolds number limits of transitional regime, heat transfer coefficient and friction factor. 


\section{Experimental set-up}

Fig. 1 shows the schematic layout of the experimental facility containing a tube-in-tube heat exchanger that forms the test section for this study. The facility consisted of two closed loops, one for cold water and the other for hot water.

The hot water loop (red line in Fig. 1) was connected to a 1000 liter reservoir (item R1) fitted with a $36 \mathrm{~kW}$ electrical resistance heater. The water was heated to a preselected temperature of approximately $50^{\circ} \mathrm{C}$, and thermostatically controlled to a temperature of within $\pm 1{ }^{\circ} \mathrm{C}$ of the selected temperature. A pump (item P1) was used to circulate the water through the loop. Two different positive displacement pumps were employed according to flow rate requirements and had delivery ranges of $0.5-3.87 \mathrm{~kg} / \mathrm{s}$ and $0.3-1.6 \mathrm{~kg} / \mathrm{s}$. Since flow rates were often required that were much less than what the pumps were rated for, a bypass line with a handoperated valve (item BV1) was utilized to control the flow rate through the test section. An accumulator (item A1) was installed downstream of the pump to dampen mass flow rate and small pressure pulsations to the inlet of the test section. The mass flow rates in the water loop were measured using a coriolis flow meter (item M1). Depending on the required flow rate a selection was made between two different flow meters which had effective ranges of $0-0.607 \mathrm{~kg} / \mathrm{s}$ and $0-1.833 \mathrm{~kg} / \mathrm{s}$ and measurement error uncertainties of $\pm 0.1 \%$ each.

The cold water loop (blue line in Fig. 1) consisted of very similar components as the hot water loop. The cold water was, however, supplied from a 5000 liter reservoir (item R2) connected to a $45 \mathrm{~kW}$ chiller unit. The water was cooled to a preselected temperature of approximately $20^{\circ} \mathrm{C}$, and thermostatically controlled to a temperature of within $\pm 1{ }^{\circ} \mathrm{C}$ of the selected temperature. The same types of pumps and flow meters utilized for the hot water loop were used in the cold water loop. In addition, both loops were fitted with filters (items 


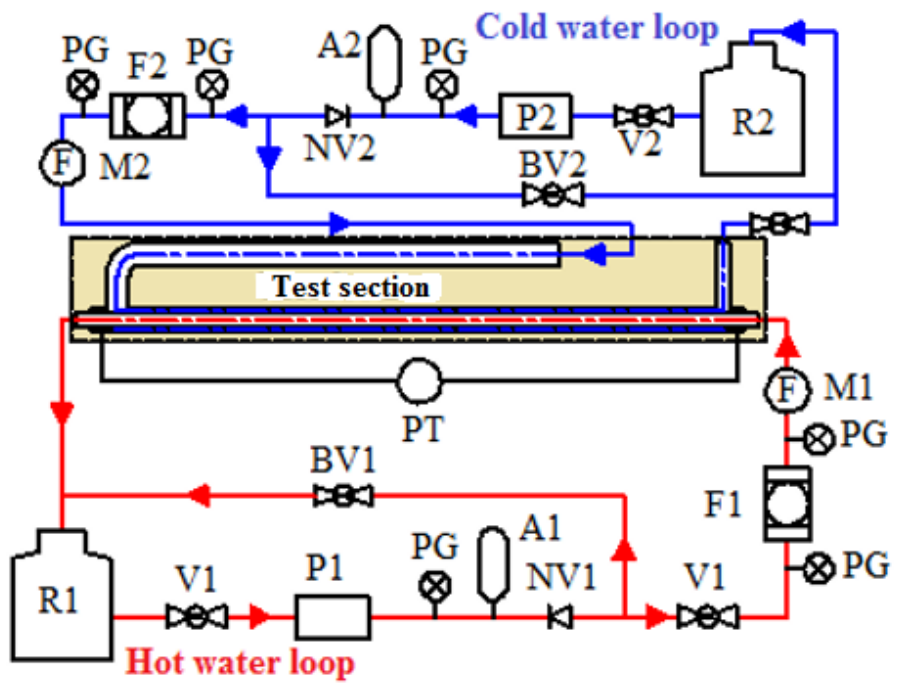

Figure 1. Schematic diagram of experimental set-up with test section. The nomenclature of the components are given in the text (Section 2). 
F1 and F2), pressure gauges (PG), non-return valves (items NV1 and NV2), valves (V1, V2), pressure relief valves, and appropriate pipes and pipe fittings.

By switching the connections between the test section inlets and outlets, and the two water loops, the operating test requirements of either hot water or cold water in the annulus could be investigated. For the heated annulus case (configuration shown schematically in Fig. 1), cold water flowed in the annular passage and hot water in the inner tube, while for cooled annuli cases it was vice versa.

The test section, schematically shown in Fig. 2, was constructed in the configuration similar to a tube-in-tube heat exchanger, with the annulus that represented the test section, and thus the focus of this study. The two tubes used were hard drawn copper tubes and the heat exchanger was positioned in a horizontal orientation. The inner tube had inner and outer diameters of $14.49 \mathrm{~mm}$ and $15.90 \mathrm{~mm}\left(D_{1}\right)$ respectively, while for the outer tube these diameters were $32.9 \mathrm{~mm}\left(D_{0}\right)$ and $35 \mathrm{~mm}$ respectively. The diameter ratio, $a=D_{1} / D_{0}$, of the annulus was 0.483 .

The heat transfer length, based on the wetted annulus surface area over which heat transfer could occur was $5.08 \mathrm{~m}\left(L_{h x}\right)$ and the pressure drop length between two pressure taps, was $5.06 \mathrm{~m}\left(L_{p d}\right)$. The pressure taps were position on the top of the annular passage, and each had an inner diameter of $1 \mathrm{~mm}$ and were placed in the stagnant flow regions $30 \mathrm{~mm}$ before and after the inlet and outlet, respectively. The diameters of the taps were far smaller than the recommended $10 \%$ of the hydraulic diameter of the annulus to avoid significant influence on the pressure readings [27]. When drilling the holes into the outside wall of the outer tube for the pressure taps, special care was taken to ensure no burrs were left behind and that the tube was smooth on the inside. Pressure drops were measured with a $2.2 \mathrm{kPa}$ pressure transducer with a measurement uncertainty of $\pm 0.0055 \mathrm{kPa}$ (item PT in Fig. 1). 


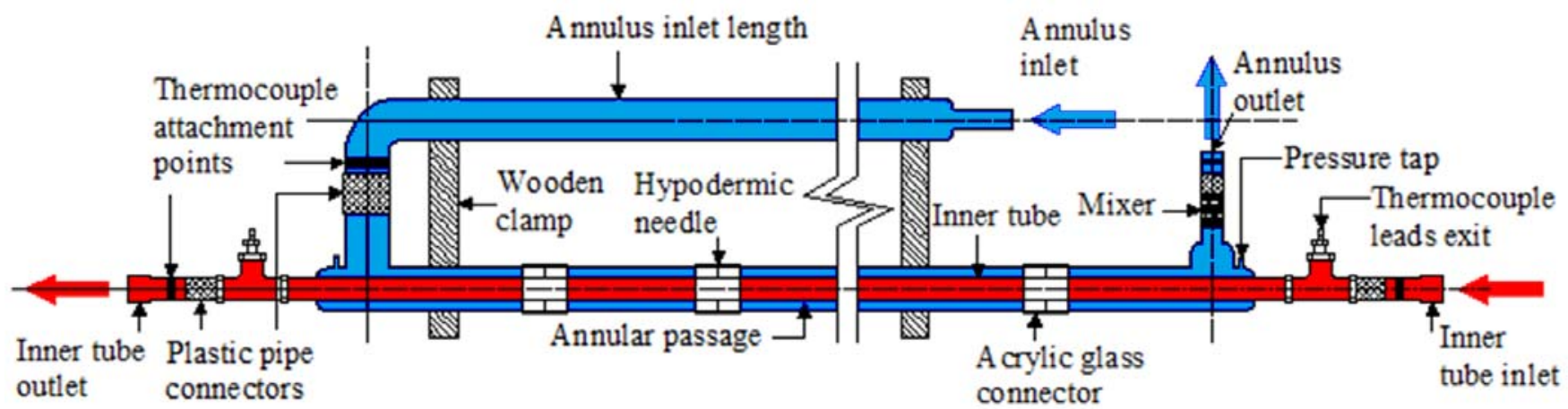

Figure 2. Schematic of the test section similar in configuration to a tube-in-tube heat exchanger test section. The annulus of the heat exchanger forms the test section. 
Since transitional flow range results could be affected by the inlet geometry [11-16], special care was taken with the inlet of the annular passage to ensure repeatable results. The annular inlet geometry was that of a $90^{\circ} \mathrm{T}$-section fitting (Fig. 2), similar to that found in most practical applications. The T-section was preceded by an isothermal inlet length which ran parallel to the main test section length and which was connected to the heat exchanger by an elbow with a mid-pipe radius of $25 \mathrm{~mm}$. The inlet length was $4.2 \mathrm{~m}$ long with an inner diameter of $32.9 \mathrm{~mm}$ and was clamped to the outer tube of the heat exchanger by three wooden supports to ensure a fixed relative position between the test section passage and the inlet length. This inlet length allowed for the flow to fully develop hydrodynamically before the elbow.

To ensure concentricity of the annular passage, the inner tube was supported by hypodermic needles ( $0.8 \mathrm{~mm}$ in diameter) at eight equally spaced axial positions. Each support position had four needles spaced $90^{\circ}$ apart circumferentially, and was held in place on the outer annular wall in thick-walled acrylic glass connectors (Fig. 2). The outer tube was therefore an assembly of nine copper sections linked to each other via carefully manufactured acrylic glass connectors, such that the outer wall of the annulus was smooth and straight.

The inlet and outlet fluid temperatures for the inner tube were measured at adiabatic (isothermal) measuring stations - each consisting of a short copper tube equipped with four thermocouples connected $90^{\circ}$ apart. The thermocouples were attached to the copper tube using silver tape. Thermally, these measuring stations were insulated from the heat exchanger to prevent axial conduction by means of rubber hoses. The average of the four thermocouples were used as the mean inlet and outlet temperatures.

The inlet and outlet temperatures of the annular passage fluid were measured in a similar manner as for the inner tube, except that each measuring station was equipped with eight thermocouples. A spiral-type in-line mixer was placed before the outlet temperature measuring station to ensure that the average water temperature 
was captured accurately. The mixer was made of 4 copper elements of alternating right and left hand 180 degree helices inserted in a $19.8 \mathrm{~mm}$ diameter and $120 \mathrm{~mm}$ long copper tube.

In order to measure local inner wall temperatures, nine equally spaced measuring stations were manufactured along the length of the inner tube. At each station two T-type thermocouples, were embedded into the wall, one at the top and the other at the bottom. In order to keep the annular passage clear from unnecessary obstructions, the thermocouple leads were passed through the inside of the inner tube. Each thermocouple junction was soldered in a groove $(10 \mathrm{~mm}$ long with a depth of $0.46 \mathrm{~mm})$ that was machined into the tube wall. The grooves were filled with solder at the measuring tips and with epoxy in the remainder of the grooves (facing downstream in terms of the annular flow) such that the outer surface of the tube remained smooth. The inlet and outlet ends for the inner tube provided exit ports for these thermocouple leads.

To measure the local outer wall temperature profiles along the length of the annular passage, two thermocouples were attached to eight measuring stations, on the outer surface of the outer tube wall at intervals exactly midway between the inner tube measuring stations. At each measuring station, one thermocouple was placed on top and the other on the bottom of the tube.

The test section and inlet and outlet measuring stations were thermally insulated from the environment by covering it with $50 \mathrm{~mm}$ thick elastomeric foam sheets with a thermal conductivity of $0.036 \mathrm{~W} / \mathrm{mK}$ at $23^{\circ} \mathrm{C}$.

A computerised data acquisition (DAQ) system was used to gather the data from the respective measuring instruments. The DAQ system consisted of a personal computer using LabVIEW software with which the measurements could be logged and with which the experimental system could be controlled. The data acquisition package used contained the necessary multiplexers, analogue-to-digital converters and terminal blocks to successfully log the data onto the computer. 


\section{Experimental procedure}

The thermocouples and the pressure transducer were calibrated before the tests were conducted. The $2.2 \mathrm{kPa}$ pressure transducer was calibrated using a water column and a manometer with an accuracy of $0.25 \%$. Thermocouples were calibrated in situ with isothermal experiments in which the water from the same storage tank was circulated for a long period of time through the annulus and inner tube at the same temperatures. The calibrations occurred, once steady state conditions were reached, which was when no temperature variations occurred for a period of $3 \mathrm{~min}$.

All thermocouples were calibrated against two PT100 resistance temperature detectors installed at the inlet and outlet of the annulus, and between the inlet and outlet of the inner tube. The calibrations were done against the average measurement of the PT100s. The calibrations were done with the water circulated at temperatures of $17{ }^{\circ} \mathrm{C}$ to $55^{\circ} \mathrm{C}$ and were done without any heat transfer occurring between the inner tube and annulus. The calibration results of the thermocouples indicated that they were accurate to within $\pm 0.1^{\circ} \mathrm{C}$.

During experimental runs, three different tests types were conducted with reference to the fluid in the annulus, namely: isothermal experiments when no heat transfer occurs (pressure drop experiments), and diabatic experiments (pressure drop and heat transfer measurements) when the annulus was either heated or cooled.

The diabatic (heated and cooled) tests were further sub-divided with reference to the longitudinal inner wall temperature profiles. These temperature profiles were identified in terms of the degree of the wall temperature uniformity, $\tau$, which was defined as the ratio of the inner wall temperature of the annular passage at the outlet (measured in Kelvin) to that at the inlet (measured in Kelvin), as shown in Eq. (1). Since the 
inner wall temperatures at the inlet and outlet were not directly measured, line-fit extrapolations from the measured wall temperature profiles where used based on the measurements taken at the nine measuring stations on the inner wall.

$$
\begin{gathered}
\tau_{h a}=\frac{\bar{T}_{i w, \text { out }}}{\bar{T}_{i w, \text { in }}} \text { (for a heated annulus) } \\
\tau_{c a}=\frac{\bar{T}_{i w, \text { in }}}{\bar{T}_{i w, \text { out }}} \text { (for a cooled annulus) }
\end{gathered}
$$

Since the annular passage was the focus of this investigation, the annular flow rate was the independent property during experimental tests while the inner tube flow rate was dependent on the annular flow rate in order to create a particular wall temperature uniformity condition. The annular Reynolds number based on the hydraulic diameter ranged from slightly above 100 to approximately 14000 in order to ensure that the transitional flow regime was adequately covered. Specific wall temperature uniformities were achieved by running the water in the inner tube at a rate relative to the flow of the water in the annulus that would give a constant temperature difference between inlet and outlet of the inner tube wall. In this investigation three degrees of wall temperature uniformity of $0.99,0.975$ and 0.965 were applied for both heated and cooled annulus cases.

The applicable temperature differences between the inlet and outlet temperature of the inner tube, the degree of wall temperature uniformity, and the wall temperature at the inlet of the inner surface of the annular passage, are given in Table 1. Considering the degree of wall temperature uniformity, (as defined by Eq. 1), to achieve an ideal uniform wall temperature, requires that the wall temperatures at the inlet and outlet on the inner tube surfaces should be equal, and $\tau$ must be 1 . It was, however, challenging to achieve this ideal condition with the experimental facility in this investigation because a very high inner flow rate would be 
Table 1. Degree of wall temperature uniformity, $\tau$, for the diabatic tests.

\begin{tabular}{|l|c|c|c|}
\hline \multirow{2}{*}{ case } & $\begin{array}{l}\text { Temperature difference on } \\
\text { the inner tube wall between } \\
\text { the inlet and outlet }\left[{ }^{\circ} \mathrm{C}\right]\end{array}$ & $\begin{array}{l}\text { Degree of wall temperature } \\
\text { uniformity, } \tau,[-]\end{array}$ & $\begin{array}{l}\text { Wall temperature at the } \\
\text { inlet of inner surface of } \\
\text { annular passage }\left[{ }^{\circ} \mathrm{C}\right]\end{array}$ \\
\hline \multirow{3}{*}{ Heated } & 2 & 0.990 & 49.6 \\
\cline { 2 - 5 } annulus & 6 & 0.975 & 48.5 \\
\cline { 2 - 5 } & 10 & 0.965 & 47.3 \\
\hline \multirow{3}{*}{ Cooled } & 2 & 0.990 & 20.1 \\
\cline { 2 - 5 } annulus & 6 & 0.975 & 20.9 \\
\cline { 2 - 5 } & 10 & 0.965 & \\
\hline
\end{tabular}


needed, or a condensing/boiling fluid in the inner tube would be required. Therefore, a wall temperature uniformity, of $\tau=0.99$, being within $1 \%$, of $\tau=1$, was treated as an approximate uniform wall temperature condition. The rest of the ratios were regarded as non-uniform wall temperature conditions.

The isothermal fluid tests (no heat transfer) were conducted at a temperature range of $19.9^{\circ} \mathrm{C}-20.8^{\circ} \mathrm{C}$ (with an average of $20.1^{\circ} \mathrm{C}$ based on all tests) while the diabatic tests were conducted with a cold temperature inlet range of $17.5^{\circ} \mathrm{C}-21.0^{\circ} \mathrm{C}$ (with an average of $19.2^{\circ} \mathrm{C}$ based on all tests) and a hot water inlet temperature range of $48.6^{\circ} \mathrm{C}-51.0^{\circ} \mathrm{C}$ (with an average of $50.1^{\circ} \mathrm{C}$ based on all tests). In all cases, the water in the inner tube and in the annular passage flowed in opposite directions.

During experimentation, all data points were logged upon reaching a steady state condition, which was when the change in average temperature of water at the outlet of annular passage was within $\pm 0.1{ }^{\circ} \mathrm{C}$ over a period of 1 minute. During this period all other inlet and outlet temperatures, as well as mass flow rates remained constant. Up to 120 data points were collected for each test data point at $10 \mathrm{~Hz}$. Energy balance errors in terms of the heat transfer rates associated with the annular and inner tube fluids were checked and recorded.

Obtaining low energy balance errors (covered in Section 4) for boundary cases with higher $\tau$ values were more challenging than for cases with a lower $\tau$ value. Furthermore, heated annulus cases had better energy balances than cooled cases. Cooled annulus cases with $\tau=0.99$ had the highest average energy balance error of $6.8 \%$ while heated annulus cases with $\tau=0.965$ had the lowest value of $0.8 \%$. This was due to the relative temperature difference magnitude in the inner tube fluid from the inlet to outlet. Smaller temperature differences of this nature resulted in higher measurement uncertainties, which were also somewhat reflected in poorer energy balances. Since the focus of the investigation was only on the annular side, the energy balance errors which resulted due to the high mass flow rates in the inner tube, was only used as relative data quality indicators. Test-case heat transfer rates for data-processing were based on the annular fluid 
temperature differences (not that of the inner passage fluid), which had a significant reduced uncertainty associated with the calculated heat transfer rate.

\section{Data reduction}

The heat transfer rates in the inner tube and annular passage were determined as in Eqns. (2) and (3), respectively.

$$
\begin{gathered}
\dot{Q}_{i}=\dot{m}_{i} c_{p, i}\left(T_{\text {in }, i}-T_{o u t, i}\right) \\
\dot{Q}_{o}=\dot{m}_{o} c_{p, o}\left(T_{i n, o}-T_{o u t, o}\right)
\end{gathered}
$$

In both equations the mass flow rates were the measured mass flow rates of the water through the inner tube or annular passage (depending on which one is relevant). The average inlet and outlet temperatures of the water were obtained from the inlet and outlet measuring stations. The specific heat values were obtained from the method of Popiel and Wojtkowiak [28] at the bulk fluid temperature of each stream. Because of an almost linear increase or decrease in fluid temperature in the inner tube, the bulk fluid temperature for the inner tube was determined by the arithmetic average between the measured inlet and outlet fluid temperatures. In contrast, at low annular Reynolds numbers, the annular bulk fluid temperature along the longitudinal direction was not linear. Thus, by using the arithmetic average between the measured inlet and outlet annular bulk fluid temperatures would often have been inaccurate. Therefore, for improved accuracy of the calculated fluid properties, the annular bulk fluid temperature profile and the measured outer wall temperature profiles were taken to be approximately the same. Based on this an improved estimation of the annular bulk fluid temperature was obtained as follows:

$$
\bar{T}_{b, 0} \cong \frac{1}{L_{h x}} \int_{x_{\text {in }}}^{x_{o u t}} \bar{T}_{o w}(x) d x
$$


where $\bar{T}_{o w}(x)$ was a polynomial fit representing the outer tube wall average temperature measurement profile. The annular passage water properties were determined at this average temperature using the empirical equations of Popiel and Wojtkowiak [28].

The energy balance error was calculated by:

$$
E B=\frac{\dot{Q}_{o}-\bar{Q}}{\bar{Q}}
$$

where

$$
\bar{Q}=\frac{\dot{Q}_{i}+\dot{Q}_{o}}{2}
$$

The average convection heat transfer coefficient, $h$, was determined from Newton's law of cooling:

$$
h=\frac{\dot{Q}_{o}}{A_{s} \Delta T_{L M T D}}
$$

where, $A_{s}=\pi L_{h x} D_{1}$ is the wetted inner annulus wall surface area with $L_{h x}$ the heat transfer length, and $D_{1}$ the inner wall diameter. The logarithm mean temperature was obtained from:

$$
T_{L M T D}=\frac{\left(\bar{T}_{\text {out }, i w}-\bar{T}_{i n, o}\right)-\left(\bar{T}_{i n, i w}-\bar{T}_{\text {out }, o}\right)}{\ln \left[\left(\bar{T}_{\text {out }, i w}-\bar{T}_{i n, o}\right) /\left(\bar{T}_{i n, i w}-\bar{T}_{\text {out }, o}\right)\right]}
$$

Here $\bar{T}_{\text {out }, i w}$, and, $\bar{T}_{i n, i w}$ are the wall temperatures at the inlet and outlet of the annulus wall, obtained from extrapolation of the measured wall temperature profile, and, $\bar{T}_{i n, o}$ and $\bar{T}_{o u t, o}$ are the average water inlet and outlet temperatures. It was found that even though the annular bulk fluid temperatures were monitored with the thermocouple measurements on the outer annular wall, the non-thermally developed nature of the flow 
did not allow for the exact calculation of local bulk fluid temperatures along the heat exchanger length. Therefore, in this paper only averaged heat transfer coefficients and not local heat transfer coefficients are presented.

The mean dimensionless Nusselt number, $\mathrm{Nu}$, for the annular passage was based on the hydraulic diameter, $D_{h}=D_{0}-D_{1}$. The mean Reynolds number, Re, in the annular passage was calculated from the average bulk fluid properties. The mean Grashof number, Gr, an important quantity in buoyancy driven flow, was calculated based on the average inner wall temperature, as measured by the embedded thermocouples and the bulk fluid properties determined by the method of Popiel and Wojtkowiak [28] at the bulk fluid temperature. The Richardson number, Ri, was calculated from the mean Grashof and Reynolds number.

The average friction factors at different Reynolds numbers were determined from the measured pressure drops over the distance between the two pressure taps as:

$$
f_{o}=\frac{2 D_{h} \Delta p}{\rho_{o} L_{p d} V_{o}^{2}}
$$

The velocity of the water in the annulus was determined from the measured mass flow rate in the annulus, and the cross sectional annulus area, and average fluid density at the bulk temperature.

An uncertainty analysis of the overall experimental procedures, focusing on the annular side, based on the method of Moffat [29], was performed. The relevant uncertainties of the measuring instruments on the test facility and detail about the averaged uncertainties of Nusselt numbers and friction factors in the transition flow regime for heated and cooled annulus cases are summarized in Table 2. 
Table 2. Experimental range of measuring instruments and uncertainties.

\begin{tabular}{|c|c|c|}
\hline & Range & Uncertainty \\
\hline Thermocouples: & \multirow{5}{*}{$-200-350^{\circ} \mathrm{C}$} & \\
\hline - Single & & $\pm 0.1^{\circ} \mathrm{C}$ \\
\hline - Local wall (average of 2 thermocouples) & & $\pm 0.075^{\circ} \mathrm{C}$ \\
\hline $\begin{array}{l}\text { - Inner tube inlet and outlet (average of } 4 \\
\text { thermocouples) }\end{array}$ & & $\pm 0.053^{\circ} \mathrm{C}$ \\
\hline - Annulus inlet and outlet ( 8 thermocouples) & & $\pm 0.038^{\circ} \mathrm{C}$ \\
\hline Flow meters & $\begin{array}{l}0-0.604 \mathrm{~kg} / \mathrm{s} \\
0.3-1.4 \mathrm{~kg} / \mathrm{s}\end{array}$ & $\begin{array}{l} \pm 0.1 \% \\
\pm 0.1 \%\end{array}$ \\
\hline Differential pressure transducer & $0-2.2 \mathrm{kPa}$ & $\pm 0.0055 \mathrm{kPa}$ \\
\hline Nusselt number (Heated annulus case) & $20-29$ & $10-1.5 \%$ \\
\hline Nusselt number (Cooled annulus case) & $15-26$ & $10-1.7 \%$ \\
\hline Friction factor (Heated annulus case) & $0.30-0.061$ & $5.6-1.6 \%$ \\
\hline Friction factor (Cooled annulus case) & $0.27-0.062$ & $4.5-1.5 \%$ \\
\hline
\end{tabular}


It was found that the maximum Nusselt number uncertainty was $10 \%$ and occurred at a laminar Reynolds number of 128. However, at higher Reynolds numbers associated with the commencement of transition, the uncertainties were significantly lower. The lowest Nusselt number uncertainties (below 2\%) occurred at the highest Reynolds numbers where the fluid flow rates were at their highest. Even though the resulted smaller temperature differences associated with higher flow rates tend to increase heat transfer uncertainty values, the lower uncertainties of the flow meter reading at high flow rates, resulted in an overall reduction in the Nusselt number uncertainty.

The maximum uncertainties of the friction factors were 5.6\% at low Reynolds numbers due to higher uncertainties of the pressure drop transducer at lower flow rates. As the Reynolds number was increased, thus reducing uncertainties in pressure drop measurement the friction factor uncertainties also reduced to uncertainties lower than $2 \%$.

\section{Validation and comparison}

Experimental friction factors and Nusselt number results were compared with correlation predictions obtained from literature to verify the test section and test procedure. Fig. 3a shows the experimental friction factor results (including the uncertainty bars) for an isothermal test in terms of the annular Reynolds number. The shape of the result curve in the figure will be discussed later but includes laminar, transitional and turbulent flow regime data points. For comparison, predictions given by Eqns. (10) and (11) are used in the laminar flow regime, while in the turbulent flow regime Eq. (12) is used.

Eq. (10) contains the well-known friction factor expression for laminar fully developed flow in circular tubes, but with an adjusted annular Reynolds number based on the hydraulic diameter: 


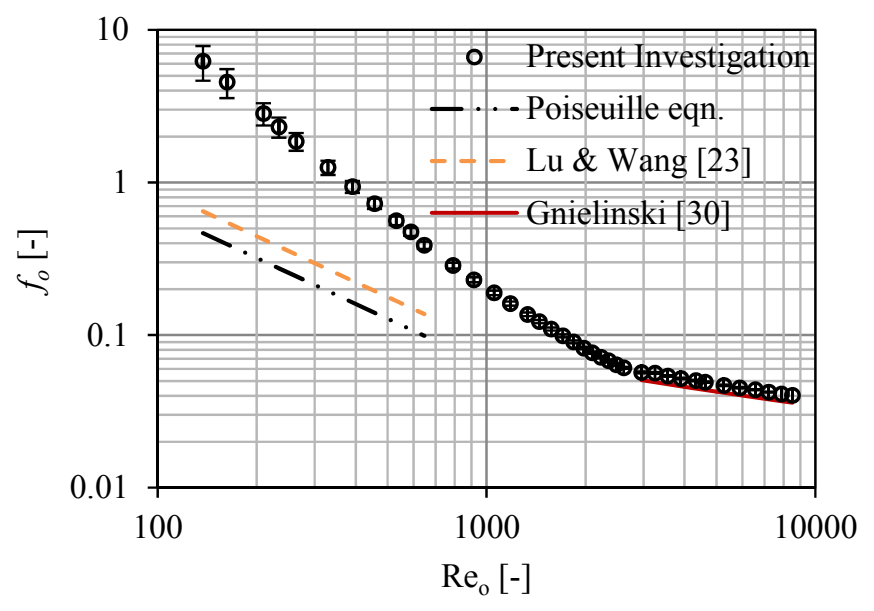

a

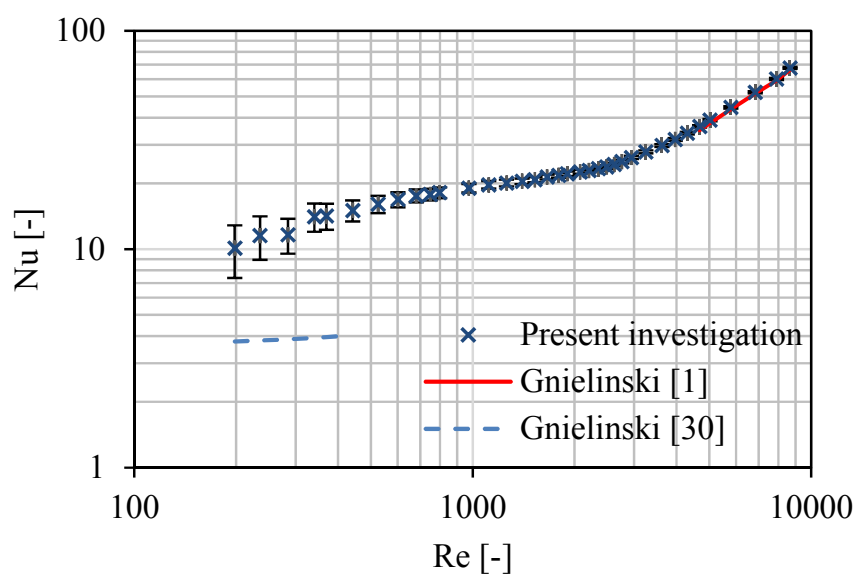

$\mathrm{b}$

Figure 3. Comparison of (a) isothermal friction factor results and (b) heat transfer results for a heated annulus case with some literature references. 


$$
f=\frac{64}{\operatorname{Re}}
$$

$\mathrm{Lu}$ and Wang [23] found the regression equation for friction factor of their narrow annulus as:

$$
f=\frac{88.9}{\operatorname{Re}}
$$

Eq. (12) was proposed by Gnielinski [30] for turbulent adiabatic friction factors in concentric annuli and uses the modified Reynolds number given in Eq. (13):

$$
f=\left(1.8 \log _{10} \operatorname{Re}^{*}-1.5\right)^{-2}
$$

where

$$
\operatorname{Re}^{*}=\operatorname{Re} \frac{\left(1+a^{2}\right) \ln a+\left(1-a^{2}\right)}{(1-a)^{2} \ln a}
$$

From Fig 3a it can be seen that in the laminar flow regime, the experimentally obtained friction factors were higher than those predicted by Eqns. (10) and (11). When compared with Eqn (10), the higher experimental friction factors could be because the annular passage had two surfaces (the outer surface of inner tube and the inner surface of the outer tube), while for a circular tube there is only the inner surface. Therefore, the influence of the additional frictional surface area is not necessarily taken into consideration by using the Reynolds number based on the hydraulic diameter. This increase in friction factor was also noted by $\mathrm{Lu}$ and Wang [23]. However, the friction factor values for the present investigation were also higher than the predictions based on Eq. (11) by Lu and Wang. This could be because both the annular diameter ratio, $a$, and the hydraulic diameter, $D_{h}$, of the present test section was different from that used by Lu and Wang [23]. In 
their investigation they had a much higher annular diameter ratio of $a=0.794$ and a much smaller hydraulic diameter of $D_{h}=6.16 \mathrm{~mm}$, compared to $a=0.483$ and $D_{h}=17 \mathrm{~mm}$ used in this study. Therefore, the Lu and Wang correlation is not necessarily applicable in the present investigation. In the turbulent flow regime, better comparison was obtained with Eq. (12) which predicted friction factors being 9.7\% lower than the experimental results.

Similarly, Fig. $3 b$ contains the Nusselt number results for the laminar and turbulent flow regimes of an arbitrary test set. The shape of the data trend will be discussed later in the paper. Uncertainty bars and some correlation predictions are also included. For comparison in the laminar flow regime, the correlation for circular tubes given in Eq. (14) from [31] is used, but based on the annular hydraulic diameter instead of a circular tube diameter; while for comparison in the turbulent flow regime, the correlation given in Eq. (15) for annular passages from [1], is used.

$$
\mathrm{Nu}=\left\{3.66^{3}+0.7^{3}+\left[1.615 \sqrt[3]{\left(\operatorname{Re} \operatorname{Pr}_{b} D_{h} / L_{h x}\right)}-0.7\right]^{3}+\left[\left(\frac{2}{1+22 \operatorname{Pr}_{b}}\right)^{1 / 6}\left(\operatorname{Re}^{1 / 6} D_{h} / L_{h x}\right)^{1 / 2}\right]^{3}\right\}^{1 / 3}
$$

$$
\mathrm{Nu}=\frac{(f / 8)(\mathrm{Re}-1000) \operatorname{Pr}_{b}}{1+12.7 \sqrt{(f / 8)}\left(\operatorname{Pr}_{b}^{2 / 3}-1\right)}\left[1+\left(\frac{D_{h}}{L}\right)^{2 / 3}\right] F_{o} K
$$

where $F_{o}=0.75 a^{-0.17}, K=\left(\frac{\operatorname{Pr}_{b}}{\operatorname{Pr}_{w}}\right)^{0.11}$ and $f$ is as in Eq. (9).

As can be seen in Fig. 3b, the experimental Nusselt numbers were significantly higher than the laminar flow regime predictions of Eq. (15). This is because Eq. (15) is for flow free from buoyance effects in circular tubes with a uniform wall temperature boundary condition while in the current investigation, significant buoyancy driven secondary flow was present. This greatly impact the heat transfer 
coefficient [18] [21]. In the turbulent flow secondary flow effects were not as dominant, therefore when compared with the Gnielinski annular flow passage correlation in Eq. (15), the experimental Nusselt numbers were within $0.8 \%$ (on average) of the predicted heat transfer coefficient for a Reynolds number range of $4680 \leq \operatorname{Re}_{o} \leq 8660$.

Based on the good agreement of the experimental results with the friction factor and Nusselt number predictions of the well-accepted Gnielinski correlations for the turbulent flow regime (Eqns. 12 and 15), the test section and test procedure used in this investigation was assumed to be validated.

Repeatability and drift of the experimental test procedure was also checked. Fig. 4 shows the Nusselt numbers of two sets of data for $\tau_{h a}=0.99$ that were taken eight months apart, during which time the first set of data (Dataset 1) and the second set of data (Dataset 2) was collected and compared. Very good repeatability was observed with the average difference in values from the two datasets being $2.5 \%$, and the maximum difference being $8.2 \%$ in the low Reynolds number range.

\section{Results}

Nusselt number and friction factor results are presented in this section for laminar, transitional and turbulent flow regimes, but special focus is placed on the transitional flow regime. Friction factors results are plotted for isothermal and diabatic wall conditions, while Nusselt number results are (by definition) only plotted for diabatic wall cases. For the diabatic cases, both heated and cooled conditions are presented - each for the three different longitudinal degrees of wall temperature uniformity.

\subsection{Richardson numbers}

Before the results can be interpreted, a better understanding of the convection types that were present in the flow regimes is needed. The boundaries between different convection types is determined by Richardson number. In general, both the free and forced convections should be considered when $0.1 \leq \mathrm{Ri} \leq 10$. For 


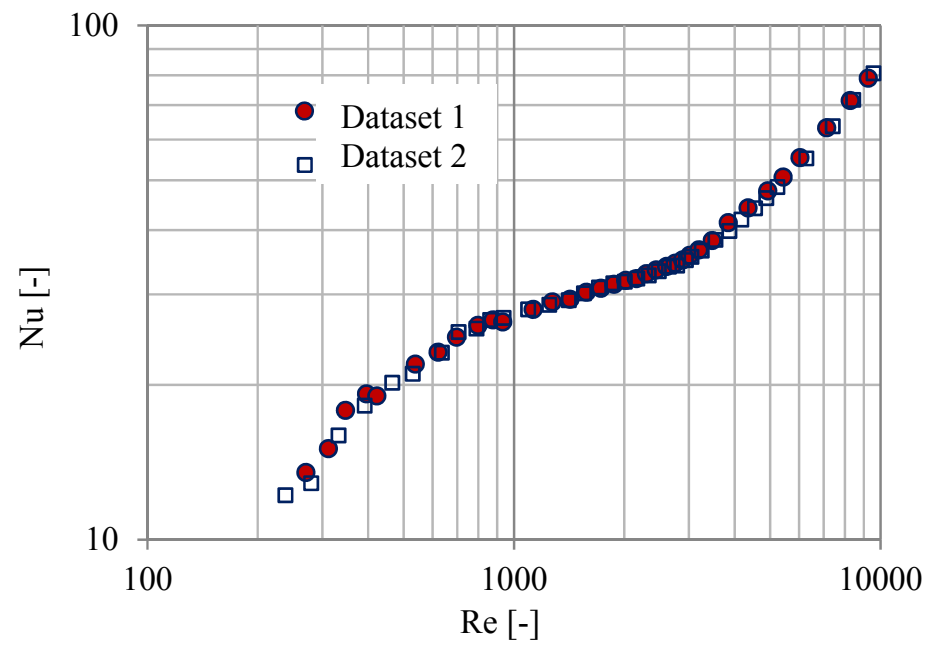

Figure 4. Plots of two similar experiments conducted at different periods, eight months apart. The data were for a heated annulus and a degree of wall temperature uniformity of, $\tau_{h a}=0.99$. 


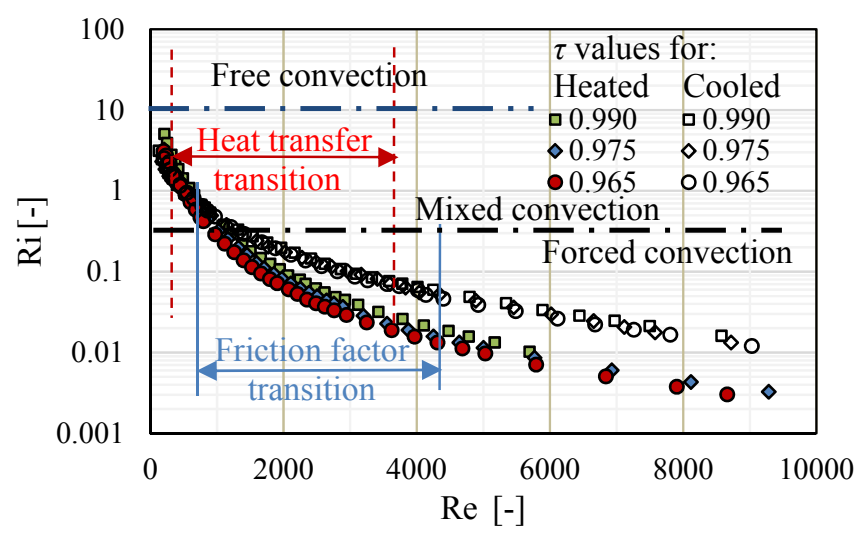

Figure 5. Richardson numbers for heated and cooled annulus cases. 
$\mathrm{Ri}>10$ the flow is treated as free convection and the pure forced convection is considered when $\mathrm{Ri}<$ 0.1. The Richardson numbers for all the relevant data points of the present investigation were calculated (based on the results that are presented in more detail in section 6.2 and 6.3) and used to determine the approximate cut off points between the forced, mixed and natural convection types. Calculated Richardson numbers for all the diabatic cases are shown in the Fig. 5. The figure also indicates the approximate Reynolds number ranges for the transitional flow regime based on the Nusselt number (red arrows and labelled as the "heat transfer transition"), and the transitional flow regime based on the friction factor (blue arrows and labelled as the "friction factor transition"). The determination of the transition ranges are discussed in more detail in the paragraphs that follow. Each test set in Figure 5 consisted of data taken at approximately 35 different mass flow rates. Of these approximately 55\% represented conditions in the transitional flow regime, $20 \%$ in the laminar flow regime, and $25 \%$ in the lower- turbulent flow regime.

In general, all the data points in laminar flow regime were in mixed convection $(10>\mathrm{Ri}>0.1)$ and those in turbulent regime were in pure forced convection $(\mathrm{Ri}<0.1)$. In the heat transfer transition range (based on the Nusselt number), $63 \%$ of data points were classified as being mixed convection conditions and the remainder were classified as pure forced convection conditions; while in the flow transition range (based on the friction factor) $50 \%$ were mixed convection conditions, and the rest were forced convection conditions.

\subsection{Heat transfer coefficients}

Fig. 6 contains the length-wise averaged heat transfer coefficients plotted in terms of the Nusselt number with respect to the Reynolds number (both on a logarithmic scale). Fig. 6a gives the results for a heated annulus, Fig. $6 \mathrm{~b}$ for a cooled annulus, and Fig. $6 \mathrm{c}$ gives the combined results of Fig. $6 \mathrm{a}$ and Fig. $6 \mathrm{~b}$.

Consider Fig 6a giving the experimentally obtained Nusselt numbers for the three heated wall temperature uniformity cases. It can be seen that: the logarithmic-scale gradient of the Nusselt number 


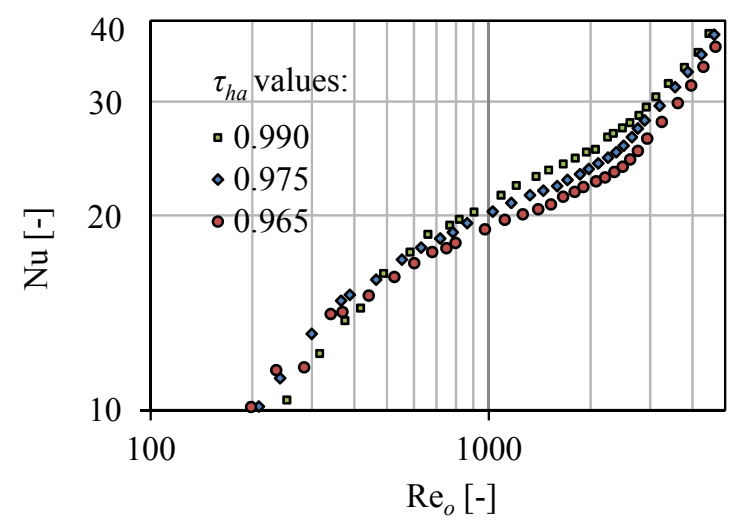

a

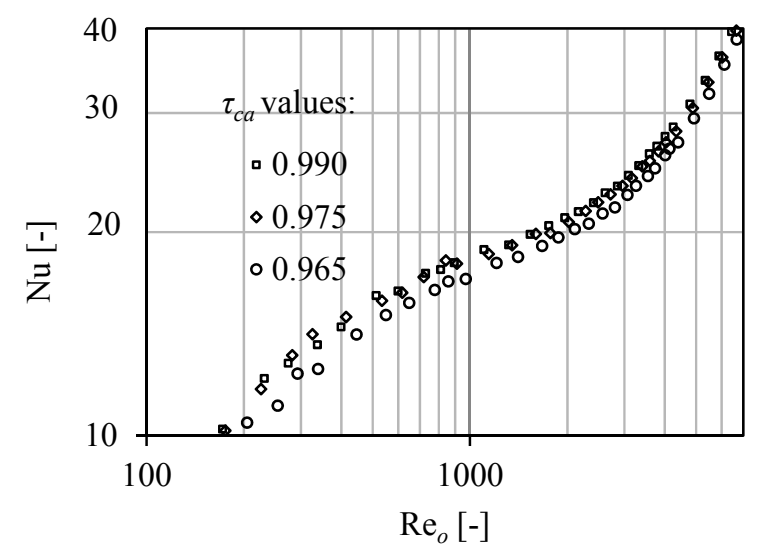

$\mathrm{b}$

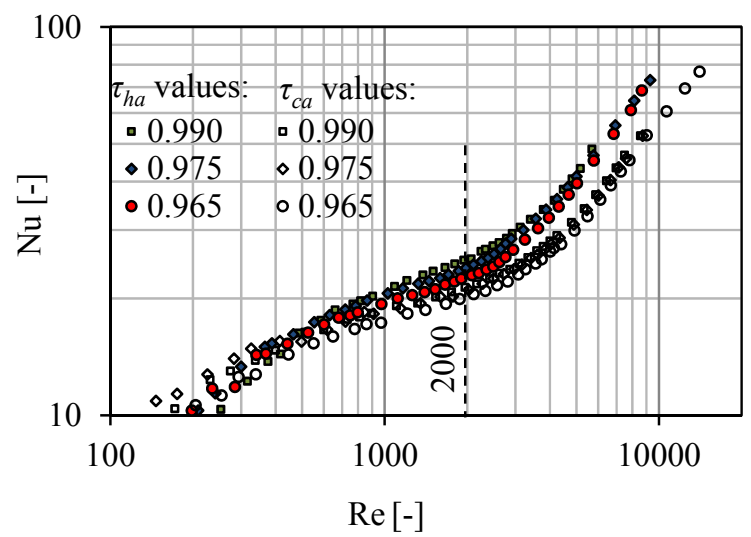

$\mathrm{C}$

Figure 6. Nusselt numbers for different degrees of wall temperature uniformity: (a) for heated annulus cases, (b) for cooled annulus cases and (c) all cases combined. 
data points was relatively steep in the low Reynolds number region, less steep the mid-range of the Reynolds numbers and steeper again in the high Reynolds number range. By inspection it was observed that the trends of the are well-described by linear line segments. The best matching set of linear line segments was determined by minimizing the overall root mean square error associated with the difference between the experimental data and the trends described by the linear line segments. An example case for the 0.990 degree of wall uniformity case is shown in Fig. 7. The mid-range region, as defined by the intersections of the three lines, indicates the transitional flow regime range while the low and high Reynolds number ranges indicate the laminar and turbulent regimes respectively. Thus, the transitional flow regime is reported in this paper as the region between the lower and upper intercepting points for the centre line segment. The Reynolds numbers for the lower and upper limit of the transitional flow regime are represented in this paper by $\mathrm{Re}_{I}$ and $\mathrm{Re}_{I I}$, respectively. This process was repeated for all wall temperature uniformity cases and diabatic states (heated or cooled).

A similar approach was followed with the friction factor results (presented in more detail in section 6.3). Table 3 gives the lower and upper Reynolds number limits of the transitional flow regime based on the Nusselt number and the friction factor data. Richardson numbers for selected values of Reynolds number for heated and cooled annulus cases and different degrees of wall temperature uniformity are also included for discussion purposes. For now, focus is only placed on the transitional flow regime limits based on the Nusselt number data.

It was found that the lower Reynolds number limits $\left(\operatorname{Re}_{I}\right)$ based on the Nusselt number for all cases are very similar, and fall in the narrow band between 350 and 500. On the other hand, the upper Reynolds number limits $\left(\operatorname{Re}_{I I}\right)$ are significantly different for different wall temperature unifroity cases and range between 3700 and 3980 for cooled cases and between 3000 and 3470 for heated cases. Based on the degree of wall temperature uniformity, the transitional flow regime Reynolds number ranges $\left(\operatorname{Re}_{I I}-\mathrm{Re}_{I}\right)$ 
Table 3. Heat transfer transition ranges and corresponding Richardson numbers at selected Reynolds numbers for heated and cooled annuli.

\begin{tabular}{|c|c|c|c|c|c|c|c|c|c|}
\hline \multirow[b]{2}{*}{ Case } & \multicolumn{2}{|c|}{$\begin{array}{l}\text { Transition } \\
\text { based on } \mathrm{Nu}\end{array}$} & \multicolumn{2}{|c|}{$\begin{array}{l}\text { Transition based } \\
\text { on } f\end{array}$} & \multicolumn{5}{|c|}{$\mathrm{Ri}=\mathrm{Gr} / \mathrm{Re}^{2}$} \\
\hline & $\operatorname{Re}_{I}$ & $\operatorname{Re}_{I I}$ & $\operatorname{Re}_{I}$ & $\operatorname{Re}_{I I}$ & $\begin{array}{l}\mathrm{Re}_{o} \\
500\end{array}$ & $\begin{array}{c}\operatorname{Re}_{o} \\
1000\end{array}$ & $\begin{array}{c}\operatorname{Re}_{o} \\
2000\end{array}$ & $\begin{array}{c}\operatorname{Re}_{o} \\
3000\end{array}$ & $\begin{array}{l}\mathrm{Re}_{o} \\
4000\end{array}$ \\
\hline$\tau_{c a}=0.99$ & 398 & 3980 & 1000 & 3980 & 0.946 & 0.460 & 0.193 & 0.10 & 0.065 \\
\hline$\tau_{c a}=0.975$ & 357 & 3800 & 1120 & 3890 & 0.947 & 0.452 & 0.177 & 0.10 & 0.059 \\
\hline$\tau_{c a}=0.965$ & 498 & 3715 & 1130 & 3800 & 1.055 & 0.467 & 0.178 & 0.091 & 0.057 \\
\hline$\tau_{h a}=0.99$ & 488 & 3470 & 1000 & 2820 & 1.384 & 0.440 & 0.100 & 0.043 & 0.023 \\
\hline$\tau_{h a}=0.975$ & 428 & 3240 & 1020 & 2700 & 1.144 & 0.343 & 0.080 & 0.034 & 0.018 \\
\hline$\tau_{h a}=0.965$ & 503 & 3020 & 1000 & 2570 & 1.000 & 0.278 & 0.066 & 0.028 & 0.015 \\
\hline Isothermal & - & - & 800 & 2500 & - & - & - & - & - \\
\hline \multicolumn{10}{|c|}{$\operatorname{Re}_{I}:$ Reynolds number at transition from laminar to transitional flow regime } \\
\hline
\end{tabular}


for cooled cases were larger than for heated cases. This could be due to differences in the strength of the buoyancy forces for the two cases. At a Reynolds number value of 500, which is close to the lower Reynolds number limit of transitional flow regimes of both cases, the values of the Richardson number for cooled and heated conditions were approximately equal to 1, as is shown in Table 3 and Fig. 5. This indicates that the influences of buoyance forces were relatively equal in magnitude for cooled and heated cases. This possibly caused transition to start at Reynolds numbers which were relatively close to each other. On the contrary, at Reynolds number values of 3000 , which is relatively close to the upper Reynolds number limit of the transitional flow regimes, cold cases had Richardson numbers that represented mixed convection condition, while the heated cases had Richardson numbers that indicated forced convection. This could be the reason why the transition flow regime Reynolds number spans $\left(\operatorname{Re}_{I I}-\right.$ $\mathrm{Re}_{I}$ ) for cooled cases were longer than for the heated cases.

It was also observed for both heated and cooled cases that $\operatorname{Re}_{I I}$ values were proportional to the $\tau$ values. Higher $\tau$ values resulted in higher $\operatorname{Re}_{I I}$ values. This is also reflected in the Richardson numbers (at $\operatorname{Re}=3000$ ). Higher $\tau$ values resulted in higher Ri values. This suggests that buoyancy forces were stronger at higher $\tau$ values which could be the cause for prolonged transition.

In the transition flow regime (refer to Fig. $6 a, 6 b$ and $6 c$ ) a definite decrease in the heat transfer coefficients was observed as the degree of wall temperature uniformity decreased. For instance, at a Reynolds number of 2000 , the Nusselt numbers for wall temperature uniformities of $\tau h a=0.975$ and $\tau h a=0.965$, were $4.4 \%$ and $9.6 \%$ lower than the $\tau h a=0.99$ case. This is directly linked to the temperature difference between the wall and the bulk fluid. Fig. 8, which presents the temperature difference between the wall and the bulk fluid for a heated case at a Reynolds number of 1000 , is used to explain this point. These difference are also higher than the average uncertainty of the Nusselt number in the transitional flow regime. 


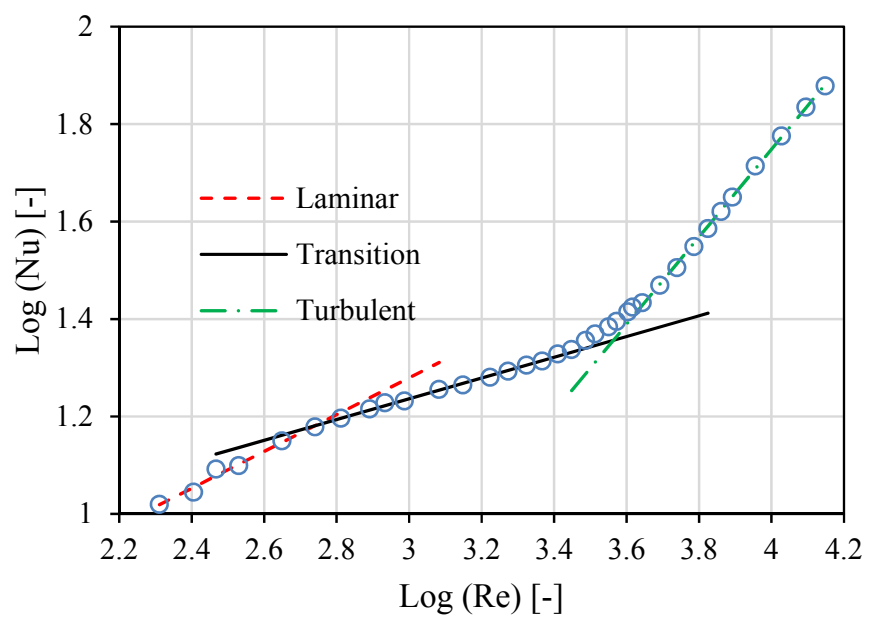

Figure 7. Determination of flow regimes. 


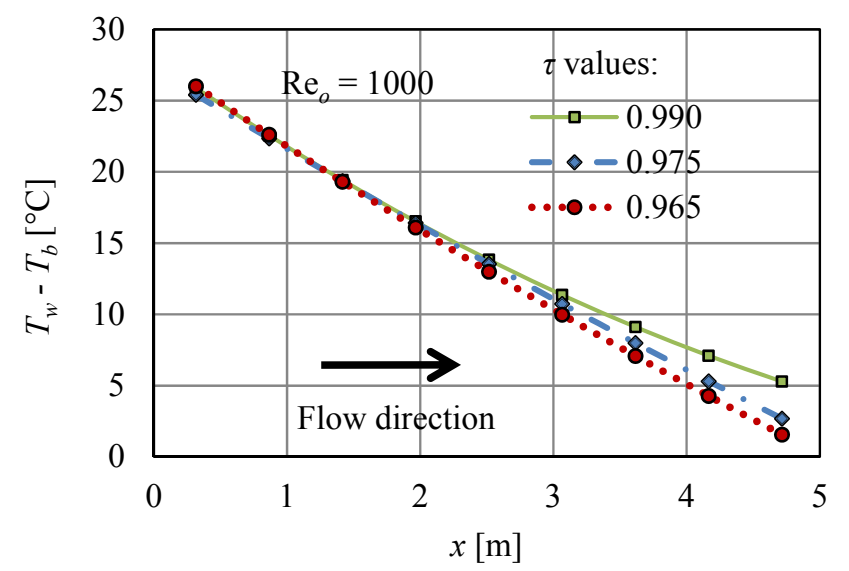

Figure 8. Temperature difference between the wall and the bulk fluid for different degrees of wall temperature uniformity on the inner wall. 
Because it was challenging to perform all the test at exactly the same Reynolds number interval values, the temperature differences in Fig. 8 were obtained by interpolating between the closest Reynolds number data points. Since the inlet temperatures for the hot and cold water were relatively constant, the temperature differences at the annulus inlet side of the heat exchanger for the three wall temperature uniformity were close to each other. At annular downstream points, an observable difference in the temperature differentials were observed at different $\tau$ values. Higher downstream temperature differentials were obtained at higher $\tau$ values. Such higher temperature differentials lead to stronger buoyancy driven flow which results in improved fluid mixing and higher heat transfer rates. In their investigation, Ciampi et al. [22] made a similar observation. For that reason the dependence of the Nusselt number on $\tau$ in Fig. 6 could have been expected.

In general, all the results (shown in Fig. 6) followed the same trend in relation to $\tau$. At closer inspection, it was found that $95 \%$ of the data points in the transitional flow regime exhibited a consistent dependency on $\tau$ which was greater in magnitude than the experimental uncertainty. Therefore, it can be concluded that the observed variation of the Nusselt number in terms of $\tau$ is not due to measurement error.

Fig. $6 \mathrm{~b}$, shows that the trends for the cooled annulus cases were similar to the heated annulus cases in Fig. 6a. The case with the highest wall temperature uniformity had the highest Nusselt numbers followed by the rest in a descending order. For instance, at a Reynolds number of 2 000, the average Nusselt numbers for the wall temperature uniformities of $\tau_{c a}=0.975$ and $\tau_{c a}=0.965$, were $2.1 \%$ and $5.4 \%$ lower than for the $\tau_{c a}=$ 0.99 case.

Similar to the observations of Van Zyl et at. [25] and Prinsloo et al. [26], it was found that for any given Reynolds number the heat transfer coefficient for heated and cooled cases were different from each other. This is shown in Fig. 6c, where the heated annulus data of Fig. 6a is compared to the cooled data of Fig. $6 \mathrm{~b}$. The results show that the heat transfer coefficients for the cooled cases were smaller than those for the heated 
cases. For instance, at a Reynolds number of 2000 , the heat transfer coefficients for heated cases at $\tau=0.99$, 0.975 and 0.965 were $18 \%, 15 \%$ and $12 \%$, higher respectively than the cooled case counterparts. This is caused by the variation of the temperature differences between the bulk annular fluid temperature and inner wall temperature of the annular passage, as well as the fluid Prandtl number (specifically the viscosity) which is relatively temperature sensitive.

Heat transfer coefficient results are also presented in terms of the average Colburn $j$-factors $\left(j=\mathrm{Nu} / \operatorname{Re} \operatorname{Pr}_{b}^{1 / 3}\right.$ ) in Fig.9. The heated annulus results are given in Fig. 9a, the cooled annulus data in Fig. 9b, and all the results combined of Figs. 9a and 9b, in Fig. 9c. The $j$-factors were found to be proportional to the $\tau$ value. Higher $\tau$ values produced higher $j$ factors. For instance, at a Reynolds number of 2000 , the Colburn $j$-factors for the heated cases at $\tau_{h a}=0.975$ and $\tau_{h a}=0.965$ were $6.4 \%$ and $13 \%$ lower than at $\tau_{h a}=0.99$. Likewise, for the cooled cases (also at a Reynolds number of 2000 ), the average $j$-factor at $\tau_{c a}=0.975$ and $\tau_{c a}=0.965$ were $1.2 \%$ and $2.9 \%$ lower.

It was also observed from the results in Fig. 9, that the $j$-factor values for a cooled annulus case were closer to each other than those for a heated case. The impact of $\tau$ was therefore more severe for heated cases than for cooled cases. This could also be due to the variation of temperature differences between the annular bulk fluid and the inner wall during heating and cooling processes. When the effect of the Prandtl number, which is dependent on the fluid viscosity, is taken into consideration, as is the case when considering the $j$-factors, it follows that the heated and cooled annulus cases behaved similarly as is depicted in Fig 9c. The percentage difference between the $j$-factors of heated and cooled annuli at a Reynolds number of 2000 , for $\tau=0.99,0.975$ and 0.965 were $+9 \%,+3.3$ and $+1 \%$, which were significantly smaller than the percentage differences based on the Nusselt number results in Fig. 6c. This indicates that a large component of the observed differences in the heated and cooled case heat transfer coefficients were in fact fluid property based, and not necessarily based on the direction of the heat flux. 


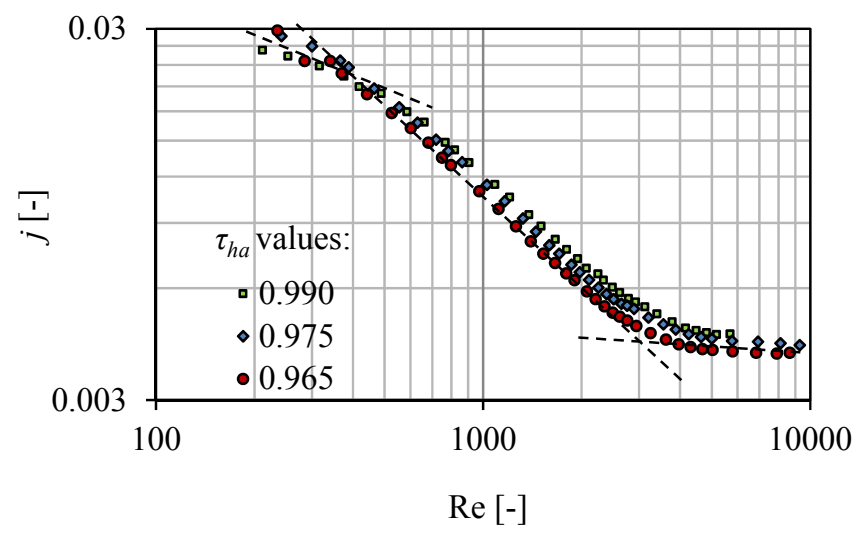

a

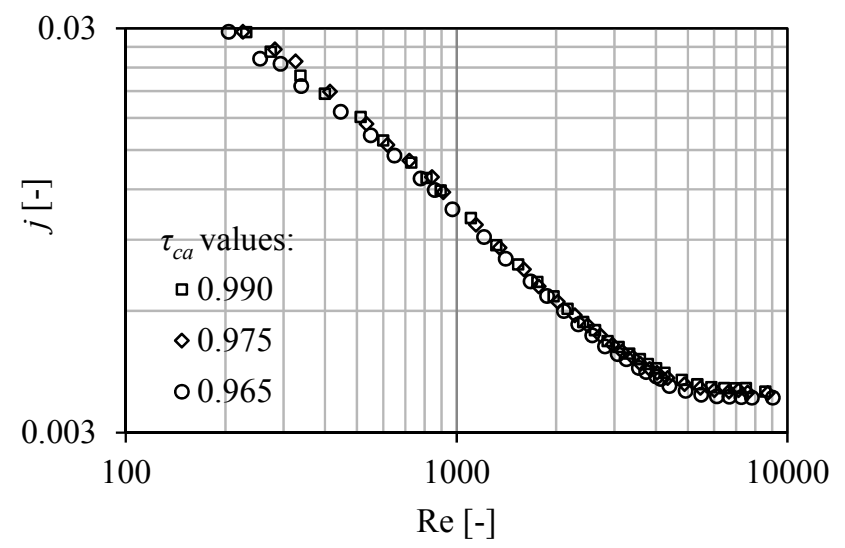

$\mathrm{b}$

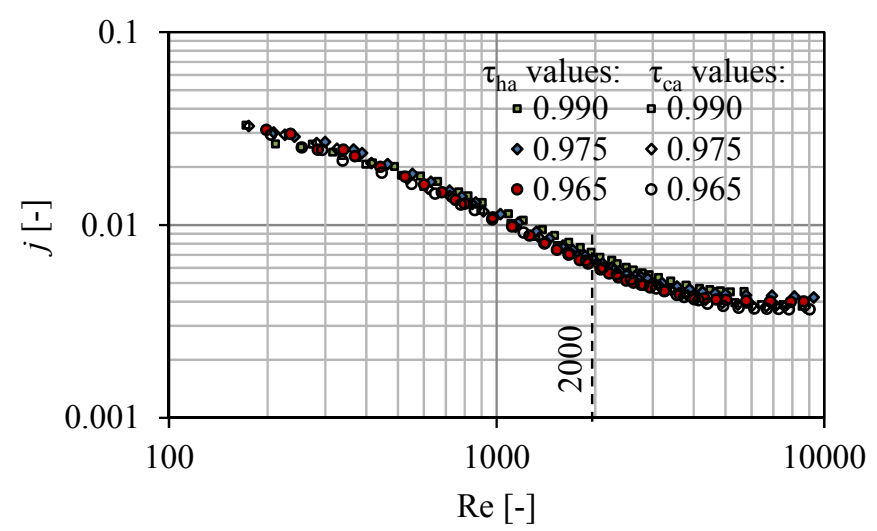

$\mathrm{c}$

Figure 9. $j$-factors for different degrees of wall temperature uniformity: (a) for heated annulus cases, (b) for cooled annulus cases and (c) all cases combined. 
However, Fig. 9c does show that the $j$-factor results for the cooled annulus and heated annulus did not fall exactly on one line, as is often the case in fully forced convection turbulent cases $[25,26]$. It was also noted that as the degree of wall temperature uniformity decreased, the heat transfer coefficients in terms of $j$ factors for the two annulus case types became more similar (not shown in the figure). This could be due to the decrease in the strength of the buoyancy force on the flow as the temperature difference between the inner wall and bulk fluid decreased. The transition ranges for $j$-factor were the same as for Nusselt number (in Table 3) and are therefore not repeated here.

\subsection{Friction factors}

The friction factor results are plotted in Fig. 10. The heated annulus results are given in Fig. 10a, the cooled annulus results are given in Fig. 10b, and all the results of Fig. 10a and 10b, are given combined in Fig. 10c. In Figs. 10a-c, the isothermal friction factor result are also given for reference purposes. It was again found from inspection that the laminar, transitional and turbulent trends were well-decribed by linear line segments on the logarithmic plots of the friction factor in terms of the Reynolds number. Likewise, the upper and lower limits of the transitional flow regime based on the friction factor results were determined from the line segment intercept points. Included in Fig. 10a, is a sample of the perceived ranges of the transitional flow regime as identified by a change in the data point gradients. For all cases, similar behaviour was observed, namely that: the friction factors rapidly decreased linearly (using logarithmic axes) with increasing Reynolds numbers in the laminar flow regime and then had a lower rate of decrease in transition and lastly had the lowest in rate of decrease in the turbulent flow regime.

As mentioned, Table 3 also gives the lower and upper Reynolds number limits of flow transition regimes $\left(\operatorname{Re}_{I}\right.$ and $\left.\operatorname{Re}_{I I}\right)$ based on the friction factor. The isothermal case had the lowest $\operatorname{Re}_{I}$ and $\operatorname{Re}_{I I}$ values as well as the smallest transitional regime Reynolds number span $\left(\operatorname{Re}_{I I}-\operatorname{Re}_{I}\right)$ of all the conditions considered. Further, 


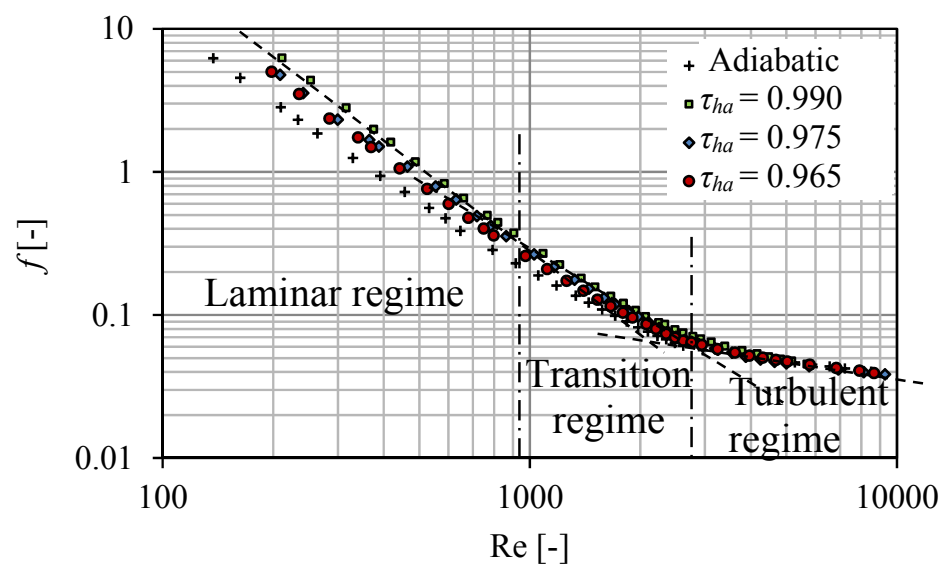

a

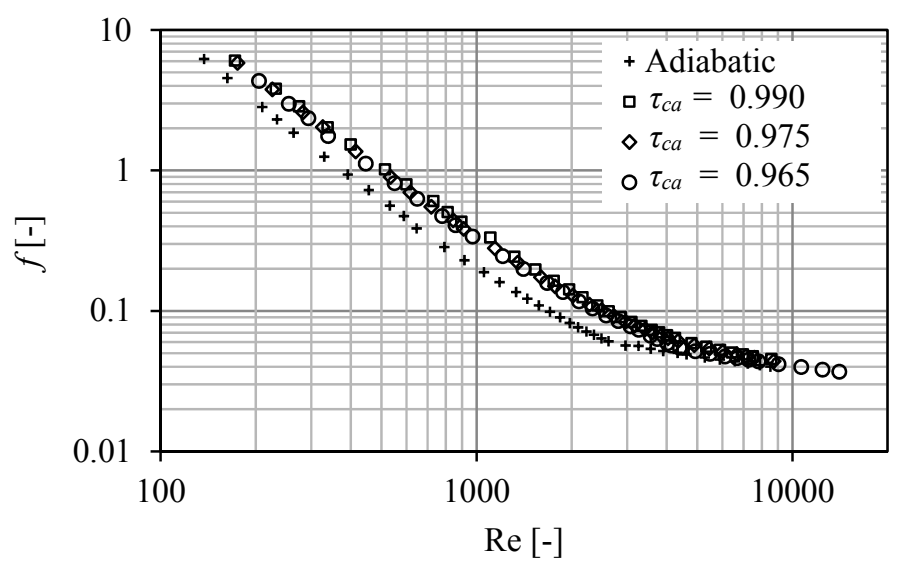

b

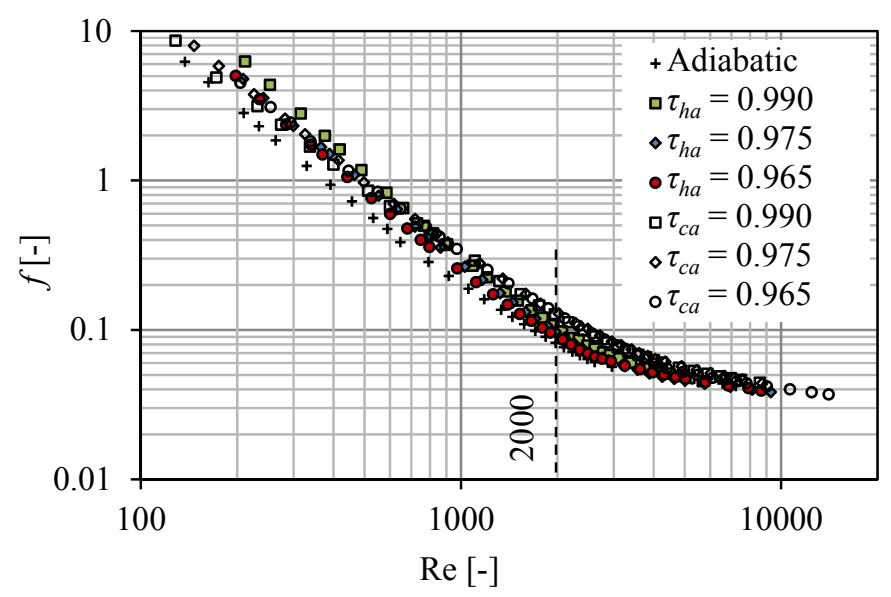

c

Figure 10. Friction factors for different degrees of wall temperature uniformity: (a) for heated annulus cases, (b) for cooled annulus cases and (c) all cases combined. 
it can be noted that heated cases had lower ReII values and transitional regime Reynold number spans than the cooled cases, irrespective of the $\tau$ value. It was also found that the transitional regime Reynolds number span length was proportional to the $\tau$ value. Higher $\tau$ values resulted in longer transition flow regime spans.

Next, we compare the $\operatorname{Re}_{I}$ and $\operatorname{Re}_{I I}$ values based on the Nusselt number with those based on the friction factor. It can be seen that these Reynolds number ranges do not coincide. Unlike with circular tubes where flow and heat transfer transition from laminar to turbulent normally start and end concurrently [16], in annular passages the transition based on the Nusselt number often starts earlier than the transition based on the friction factor. This is also the case in this study and reflects similar observations that were made by $\mathrm{Lu}$ and Wang $[23,24]$ for a narrow annulus. For instance, at $\tau_{h a}=0.99$, transition based on the Nusselt number started and ended at Reynolds numbers of approximately 430 and 3240, while for the transition based on the friction factor, it started and ended approximately at 1000 and 2 700. The delayed transition based on the friction factor was present in all the cases considered. The difference in the lower and upper Reynolds number limits of the transitional regimes is due to the fact that the friction factor is influenced by two stationary boundaries (the outer and inner wall surfaces) while, with the outer wall insulated, the heat is only transferred at the inner wall surface.

Returning to Fig. 10, it was found that higher $\tau$ values resulted in higher friction factors in the laminar and transition flow regimes, but in the turbulent flow regime such variations were insignificant. At a Reynolds number of 2000 the average friction factor for the heated case for $\tau$ ha values of $0.99,0.975$ and 0.965 were $27 \%, 18 \%$ and $12 \%$ higher than the isothermal friction factor case. While for the cooled annulus case the average friction factor for $\tau_{c a}$ values of $0.99,0.975$ and 0.965 were $72 \%, 61 \%$ and $56 \%$ higher than the isothermal friction factor case. 
This phenomenon could be caused by various factors including the different values of viscosity on the inner wall as determined by different wall temperature uniformities. For instance, when considering a cooling case (with warm water in the annulus and cold water in the inner tube), a higher value of $\tau$ would mean a lower average temperature on the inner wall of the annulus, which would result in higher wall fluid viscosity and higher shear forces on the wall. This would increase the perceived friction factor. As an example, by considering $\mathrm{Re}=2000$ for a cooled case, the increases in friction factor based on its dependence on the fluid viscosity and radial velocity gradient, $\mu d v / d r$ )( would be approximately $50 \%, 39 \%$, and $32 \%$ above the isothermal friction factor (for forced convection). As these values are much lower than the increases in the experimental friction factors mentioned earlier, it can be concluded that the increase in friction factors are partly due to the secondary flow in the annulus. The higher the temperature difference between the inner wall of the annular passage and annular bulk fluid temperature, the higher the buoyance forces will be, and the stronger the secondary flow, which will increase the friction factors. That could be the reason the annulus with the highest degree of wall temperature uniformity of $\tau_{c a}=0.99$ had the highest friction factors if compared to the other two cases with wall temperature uniformities of 0.975 and 0.965 .

In a similar fashion, for a heated case a reduction in the friction factor would be expected if it was only dependent on viscosity, but in this investigation these friction factors were found to be also increasing with an increase in the degree of wall temperature uniformity. Therefore, the presence of buoyancy induced secondary flow is believed to be the cause of the increased friction factor.

\section{Heat transfer correlation}

In cases with internal mixed convection, the heat transfer coefficient depends on the Grashof number, Prandtl number, Reynolds number, and the physical properties of the fluid at the wall, as well as the geometry and orientation of the flow passage. In this paper we only consider one flow passage geometry, being a concentric horizontal annulus with an annular diameter ratio of 0.483 . The intention is to first correlate the impact of the 
wall temperature uniformity specifically, before attempting to include additional geometric influences, which falls beyond the scope of this paper.

Unlike with circular tubes, where transition is metastable and complicated as explained by Zhipeng [32], transition in the annular passage is more orderly. This conclusion can be drawn judging by the linear appearance of the Nusselt number, $j$-factor and friction factor versus Reynolds number relationships (using logarithmic scales) in Figs. 6, 9 and 10 in the transitional flow regime. Mohammed [21] used eqn. (16) to develop correlations associated with mixed convection.

$$
\mathrm{Nu}_{o}=C\left(\mathrm{Gr}_{o} \operatorname{Pr}_{b} / \operatorname{Re}_{o}\right)^{n}
$$

In this study eqn. (16) has been modified in order to take into account of different degrees of wall temperature uniformity and is of the form:

$$
\mathrm{Nu}=C_{1} \tau^{n}
$$

where

$$
C_{1}=B_{1}\left(\frac{\mathrm{Gr} \operatorname{Pr}}{\operatorname{Re}}\right)^{z_{1}}
$$

and

$$
n=B_{2}\left(\frac{\mathrm{GrPr}}{\operatorname{Re}}\right)^{z_{2}}
$$

A common transitional regime range for the three wall temperature boundaries was used for the purposes of deriving correlations. The maximum value of all the lower Reynolds number limits and the minimum value of all the upper Reynolds number limits were considered as the lower and upper limits of the common 


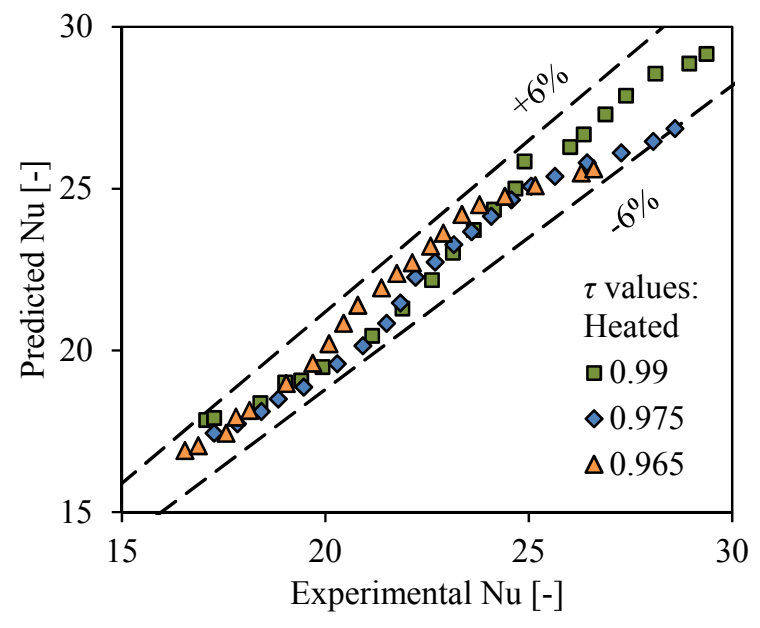

$\mathrm{a}$

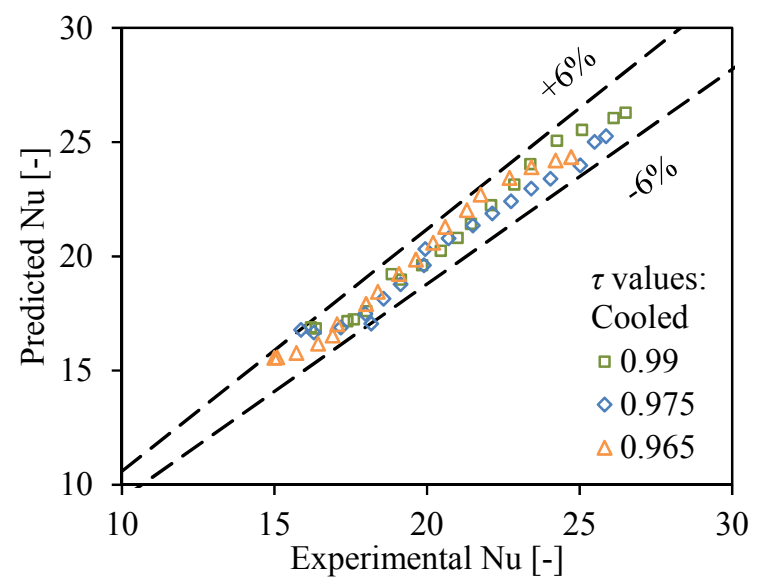

b

Figure 11. Comparison between experimental and predicted heat transfer transition results for (a) heated and (b) cooled annulus cases. 
Table 4. Constants, exponents and application ranges of proposed correlations for heated and cooled annulus cases.

\begin{tabular}{|c|c|c|c|c|c|}
\hline \multirow[t]{2}{*}{ Case } & \multicolumn{2}{|c|}{ Coefficients } & \multicolumn{2}{|c|}{ Exponents } & \multirow[t]{2}{*}{ Application range } \\
\hline & $B_{1}$ & $B_{2}$ & $Z_{1}$ & $Z_{2}$ & \\
\hline $\begin{array}{l}\text { Heated } \\
\text { annulus }\end{array}$ & 417.42 & 132.24 & -0.39 & -0.415 & $\begin{array}{l}500 \leq \operatorname{Re} \leq 30004.3 \\
\leq \operatorname{Pr} \leq 6.2 \\
520 \leq \mathrm{GrPr} / \operatorname{Re} \leq 2900 \\
0.965 \leq \tau \leq 0.990\end{array}$ \\
\hline $\begin{array}{l}\text { Cooled } \\
\text { annulus }\end{array}$ & 1466 & 356.34 & -0.566 & -0.597 & $\begin{array}{l}500 \leq \operatorname{Re} \leq 37003.8 \\
\leq \operatorname{Pr} \leq 5.2 \\
960 \leq \mathrm{GrPr} / \operatorname{Re} \leq 2500 \\
0.965 \leq \tau \leq 0.990\end{array}$ \\
\hline
\end{tabular}


transitional regime range, respectively. The values of the constants and exponents for eqns. (18) and (19) are shown in Table 4 together with ranges of applicability.

Fig. 11 shows the comparison between experimental results and the predicted Nusselt number for (a) heated annulus case and (b) cooled annulus case. The agreement between the experimental results and the proposed correlations was good, with all the data points being predicted within a $\pm 6 \%$ error band for both the heated and cooled annulus case.

\section{Friction factor correlation}

It was mentioned that the study of the isothermal pressure drop was included in this investigation for referencing purposes. Therefore, its correlation was developed first. The diabatic cases were then developed based on the isothermal correlation. Friction factors correlations were developed within Reynolds number range of $1200-2500$ being the maximum and minimum values of all the lower and upper Reynolds number limits of all the test that were considered in this study. The best line fit in the transition regime of the isothermal friction factor plot was a power form line, the same as in Eq. (10), and is represented by Eq. (20). This equation represents all the experimental data to within $\pm 4 \%$.

$$
f_{\text {iso }}=998.65 \mathrm{Re}^{-1.237}
$$

Since the degree of the wall temperature uniformity affected the friction factors, the correlation for the diabatic transition regime were developed also in terms of the wall temperature uniformity value. Based on the form of the reference eqn. (20), diabatic correlations were developed in terms of the viscosity ratio (viscosity of the bulk fluid divided by the viscosity of the fluid on the annulus wall), and the wall temperature uniformity value to account for heat transfer effects. The proposed correlation is of the form: 


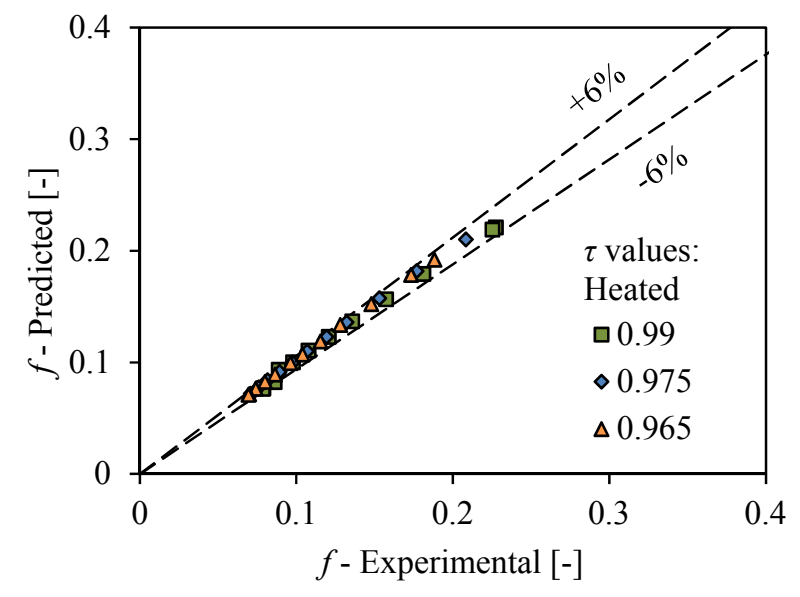

a

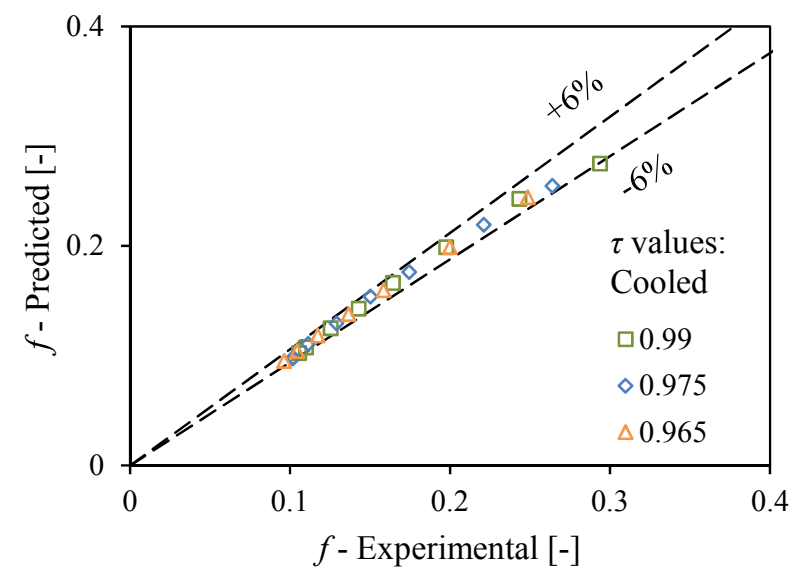

b

Figure 12. Comparison between experimental and proposed correlations for transition friction factors for (a) heated and (b) cooled annulus. 
Table 5. Constants, exponents and application ranges of proposed friction factor correlations for heated and cooled annulus cases.

\begin{tabular}{|l|l|l|l|l|l|l|l|}
\hline Case & \multicolumn{3}{|c|}{ Coefficients } & \multicolumn{2}{l|}{ Exponents } & \multicolumn{2}{l|}{ Application range } \\
\cline { 2 - 6 } & $E_{1}$ & $E_{2}$ & $E_{3}$ & $u$ & $v$ & $Z_{2}$ & \\
\hline Heated & 265 & -2.03 & -1.66 & 0.07 & 1.12 & -2.03 & $1200 \leq \mathrm{Re} \leq 2500,15.24 \leq \mathrm{Gr}^{u} \operatorname{Pr}^{v} \leq 18.2$, \\
annulus & & & & & & & $1.32 \leq \mu_{b} / \mu_{i w} \leq 1.5,0.990 \leq \tau \leq 0.965$ \\
\hline Cooled & 4.23 & -0.14 & 10.2 & 0.07 & 1.12 & -0.17 & $1200 \leq \operatorname{Re} \leq 2500,12.17 \leq \mathrm{Gr}^{u} \operatorname{Pr}^{v} \leq 14.09$, \\
annulus & & & & & & & $0.65 \leq \mu b / \mu_{i w} \leq 0.78,0.990 \leq \tau \leq 0.965$ \\
\hline
\end{tabular}




$$
f_{d}=f_{i s o} C_{2}\left(\frac{\mu_{b}}{\mu_{i w}}\right) \tau^{m}
$$

The dependency of friction factor on the buoyancy force are taken into account by Grashof number and Prandtl number in the constant, $C$ and exponent $m$ in the form:

$$
\begin{gathered}
C_{2}=E_{1}\left(\operatorname{Gr}^{u} \operatorname{Pr}^{v}\right)^{z_{2}} \\
m=E_{2}\left(\operatorname{Gr}^{u} \operatorname{Pr}^{v}+\right) E_{3}
\end{gathered}
$$

The values of the constants and exponents for eqns. (22) and (23) are shown in Table 5 together with ranges of applicability.

Fig. 12 shows the comparison between the experimental and predicted friction factor for (a) heated case and (b) cooled case. The agreement between the experimental results and proposed correlations was good, with all the data points, within a $\pm 6 \%$ error band for both the heated and cooled annulus cases.

\section{Conclusions}

Heat transfer characteristics in a concentric horizontal annular passage were experimentally investigated for developing flow associated with secondary flows in liquid water. The annular diameter ratio was 0.483 and the averaged inlet temperatures for hot and cold water were approximately $50^{\circ} \mathrm{C}$ and $19^{\circ} \mathrm{C}$, respectively. The inner surface of the annular passage had non-uniform longitudinal wall temperature profiles which were expressed in terms of a degree of wall temperature uniformity while the outer wall was isothermal. Heated 
and cooled annulus cases were investigated in all heat transfer and fluid flow regimes but special attention was given to the transition flow regime.

For both heated and cooled annulus cases heat transfer coefficients in terms of the Nusselt number were found to be directly proportional to the degree of wall temperature uniformity. Cases with high degrees of wall temperature uniformity had higher Nusselt numbers than the ones with a lower degrees of wall temperature uniformity. Nusselt numbers for heated annulus cases were higher than those for cooled annulus cases and can be attributed to the temperature dependent bulk fluid properties of the fluid.

Friction factors for diabatic cases were higher than for isothermal case in the laminar and transition flow regimes; furthermore, friction factors for cooled annulus cases were higher than for the heated annulus cases. No significant difference in friction factor values was observed in the turbulent flow regime for all the case types. The friction factors for a heated case were also found to be directly proportional to the degree of wall temperature uniformity in the transition flow regime. Another important observation was that the flow regime transition based on the Nusselt number started earlier than the transition based on the friction factor.

Correlations for the Nusselt number and friction factor in the transitional flow regime were developed. The Nusselt number correlation predicts all the experimental data within a $\pm 6 \%$ error band for the heated annulus case and $91 \%$ within a $\pm 6 \%$ error band for the cooled annulus case. The friction factor correlation predicts all data points within a $\pm 6 \%$ error band.

\section{Recommendations and further work}

This paper only reports on experimental data produced for a single annular diameter ratio and a single hydraulic diameter. Since mixed convection flow fields are dependent on the geometrical proportions of the 
flow passage, additional investigation is needed to ascertain what impact the diameter ratio and hydraulic diameter might have on the transitional flow regime behaviour. 


\section{References}

[1] Gnielinski V., Turbulent heat transfer in annular spaces - A new comprehensive correlation, Heat Transfer Engineering, Vol. 36, 2015, pp. 787-789.

[2] Swamee, P.K., N. Aggarwal, and V. Aggarwal, Optimum design of double pipe heat exchanger. International Journal of Heat and Mass Transfer, 2008. 51(9-10): pp. 2260-2266.

[3] Dirker J., and Meyer J.P., Heat transfer coefficients in concentric annuli, Journal of Heat Transfer, Vol. 124, 2004, pp. $1200-1203$.

[4] Meyer J.P., Heat transfer in tubes in the transitional flow regime, Proceedings of the $15^{\text {th }}$ International Heat Transfer Conference, Kyoto, Japan, Paper number KN03, 10-15 August, 2014.

[5] Olivier, J.A., and Meyer, J.P., Single-phase heat transfer and pressure drop of the cooling of water inside smooth tubes for transitional flow with different inlet geometries, American Society of Heating, Refrigerating and Air-Conditioning Engineers, Vol. 16, Issue 4, 2010, pp 471-496.

[6] Nunner, W., Heat transfer and pressure drop in rough tubes, VDI-Forschungsheft, 55-B, 1956, pp 5 39.

[7] Obot, N.T., Esen, E.B., and Rabas, T.J., The role of transition in determining friction and heat transfer in smooth and rough passages, International Journal of Heat Mass Transfer, Vol. 33, 1990, pp 2133 2143.

[8] Withers, J.G., Tube-side heat transfer and pressure drop for tubes having helical internal ridging with turbulent/transitional flow of single phase fluid: Part 1 - Single-helix ridging. Heat Transfer. Eng. 2, 1980, pp. $48-58$.

[9] Withers, J.G., Tube-side heat transfer and pressure drop for tubes having helical internal ridging with turbulent/transitional flow of single phase fluid: Part 2 - Multiple-helix ridging. Heat Transfer. Eng. 2, 1980 , pp. $43-50$.

[10]Manglik, R.M., and Bergles, A.E., Heat transfer and pressure drop correlations for twisted-tape inserts in isothermal tubes: Part 1 - Laminar flows, Journal of Heat Transfer, Vol. 115, 1993, pp 881 - 889. 
[11] Ghajar, A.J., and Tam, L., Heat transfer measurements and correlations in the transition for a circular tube with three different inlet configurations. Experimental Thermal and Fluid Science, Vol. 8, 1994, pp 79-90.

[12] Ghajar, A.J., and Madon, K.F., Pressure drop measurements in the transition region for a circular tube with three different inlet configurations. Experimental Thermal and Fluid Science, Vol. 5, 1992, pp 129 -135 .

[13] Ghajar, A.J., and Tam, L., Effect of inlet geometry and heating on the fully developed friction factor in the transition region of a horizontal tube. Experimental Thermal and Fluid Science, Vol. 15, 1997, pp $52-64$.

[14]Olivier, J.A., and Meyer, J.P., Transitional flow inside enhanced tubes for fully developed and developing flow with different types of inlet disturbances: Part I - Adiabatic pressure drops, International Journal of Heat and Mass Transfer, Vol. 54, 2011, pp 1587 - 1597.

[15]Olivier, J.A., and Meyer, J.P., Transitional flow inside enhanced tubes for fully developed and developing flow with different types of inlet disturbances: Part II - Heat transfer, International Journal of Heat and Mass Transfer, Vol. 54, 2011, pp 1598 - 1607.

[16] Dirker J., Meyer J.P., and Garach D.V., Inlet flow effects in micro-channels in the laminar and transitional regimes on single-phase heat transfer coefficients and friction factors, International Journal of Heat and Mass Transfer, Vol. 77, 2014, pp. 612-626.

[17] Everts M., Ayres R.S., Houwer F.A.M., Vanderwagen C.P., Kotze N.M., and Meyer J.P., The influence of surface roughness on heat transfer in the transitional flow regime, Proceedings of the $15^{\text {th }}$ International Heat Transfer Conference, Kyoto, Japan, Paper number 8338, 10-15 August, 2014.

[18] Kakaç S., Shah R.K., and Aung W., Handbook of single-phase convective heat Transfer. New York: Wiley Interscience, 1987.

[19] Hattori N., Combined free and forced convection heat transfer for fully developed laminar flow in horizontal concentric annuli (numerical analysis), JSME Trans., Vol. 45, 1979, pp. 227-239. 
[20] Nguyen T.H., Vasseur V., Robillard L., and Chandra Shekar B., Combined free and forced convection of water between horizontal concentric cylinders, Journal of Heat Transfer, Vol. 1, 1988, pp. 3-17.

[21] Mohammed, H.A., Campo, A., and Saidur, R., Experimental study of forced and free convective heat transfer in the thermal entry region of horizontal concentric annuli. International Communication in Heat and Mass Transfer, Vol. 37, 2010, pp 739-747.

[22] Ciampi, M., Faggiani, S., Grassi, W., and Tuoni, G., Mixed convection heat transfer in horizontal, concentric annuli for transitional flow conditions. International Journal of Heat and Mass Transfer, Vol. 30, 1987, pp 833-841.

[23]Lu G., and Wang J., Experimental investigation on flow characteristics in a narrow annulus, Heat and Mass Transfer, Vol. 44, 2008, pp. 495-499.

[24]Lu G., and Wang J., Experimental investigation on heat transfer characteristics of water flow in a narrow annulus, Applied Thermal Engineering, Vol. 28, 2008, pp. 8-13.

[25] VanZyl, W.R., J. Dirker, and J.P. Meyer, Single-phase convective heat transfer and pressure drop coefficients in concentric Annuli, Heat Transfer Engineering, 34(13), pp. 1112-1123, (2013).

[26] Prinsloo F.P.A., Dirker J., and Meyer J.P., Heat transfer and pressure drop characteristics in the annuli of tube-in tube heat exchangers (Horizontal lay-out), Proceedings of the $15^{\text {th }}$ International Heat Transfer Conference, Kyoto, Japan, Paper number 9225, 10-15 August, 2014.

[27] Rayle R.E., Influence of orifice geometry on static pressure measurements, ASME, Paper No. 59-A$234,1959$.

[28] Popiel C.O., and Wojtkowiak J., Simple Formulas for Thermophysical Properties of Liquid Water for Heat Transfer Calculations (from $0^{\circ} \mathrm{C}$ to $150^{\circ} \mathrm{C}$ ), Heat Transfer Engineering, Vol. 19, 1998, pp. 87-101.

[29] Moffat R.J., Describing the uncertainty in experimental results, Experimental Thermal Fluid Science, Vol. 105, 1983, pp. 498-504.

[30] Gnielinski, V., Heat Transfer Coefficients for Turbulent Flow in Concentric Annular Ducts, Heat Transfer Engineering, vol. 30, 2009, pp. 431-436. 
[31] Gnielinski, V., Heat transfer in laminar flow, in: VDI Heat Atlas, 2 ed., Springer Verlag, 2010, (Chapter G1, Section 3)

[32] Zhipeng, D., New correlative model for fully developed turbulent heat and mass transfer in circular and noncircular ducts, Trans. ASME J. Heat Transfer, Vol. 134, 2012. 